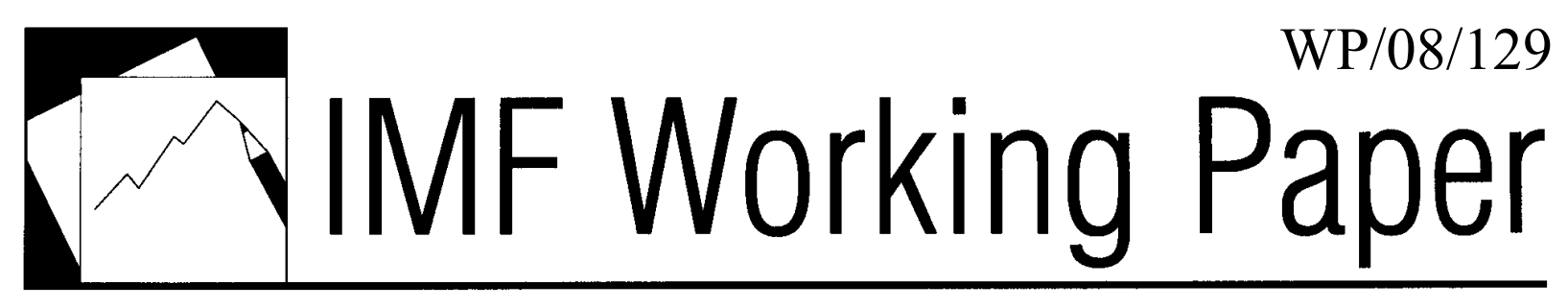

\title{
Tax Administration Reform and Fiscal Adjustment: The Case of Indonesia (2001-07)
}

John Brondolo, Carlos Silvani, Eric Le Borgne, and Frank Bosch 



\title{
IMF Working Paper
}

Fiscal Affairs Department

\section{Tax Administration Reform and Fiscal Adjustment: The Case of Indonesia \\ (2001-07)}

\section{Prepared by John Brondolo, Carlos Silvani, Eric Le Borgne and Frank Bosch ${ }^{1}$}

May 2008

\begin{abstract}
This paper should not be reported as representing the views of the IMF. The views expressed in this paper are those of the authors and do not necessarily represent those of the IMF or IMF policy.

Tax administration reforms can play an important role in fiscal adjustment. This role is examined by reviewing Indonesia's tax reform cum fiscal adjustment experience since 2001 . The paper describes Indonesia's fiscal adjustment strategy, its tax administration reforms, and assesses the impact of these reforms on fiscal adjustment. Evidence suggests tax administration improvements had a strong positive impact on the tax yield and a positive effect on the investment climate. Lessons are presented for designing tax administration reforms within the context of a fiscal adjustment program and reform priorities are identified for Indonesia's ongoing efforts to strengthen tax administration.
\end{abstract}

Keywords: Indonesia, tax administration, fiscal adjustment

Author’s E-Mail Address: jbrondolo@imf.org, csilvani@gmail.com, eleborgne@imf.org, and frank.bosch@ihug.co.nz

\footnotetext{
${ }^{1}$ The authors would like to thank Teresa Ter-Minassian, Daniel Citrin, Jeffrey Davis, Victoria Perry, Michael Keen, Rick Fisher, Anthony Pellechio, Stephen Schwartz, Benjamin Bingham, Anita Thacker, Yougesh Khatri, Amine Mati, Stanley Shrosbree, and other colleagues from the IMF and Indonesia's Directorate General for Taxation for their helpful comments and guidance. Views and errors are the authors alone, and should not be attributed to the International Monetary Fund, its Executive Board, or its management.
} 
Introduction

I. The Context for Tax Administration Reform in Indonesia ............................................

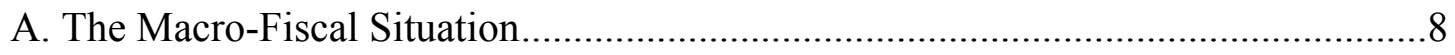

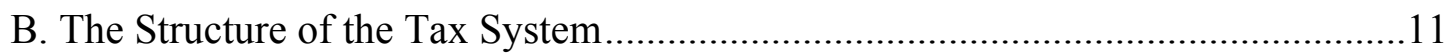

C. The State of Tax Administration ............................................................................ 14

II. The Tax Administration Reform Strategy........................................................... 16

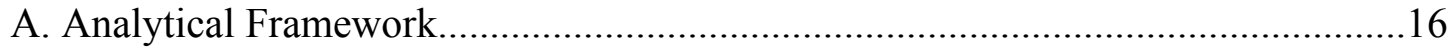

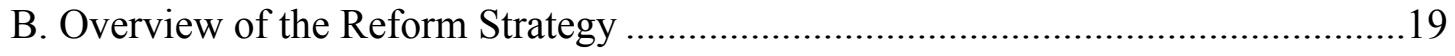

III. The Short-Term Reforms ....................................................................................22

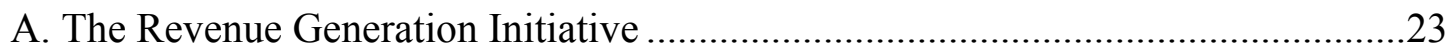

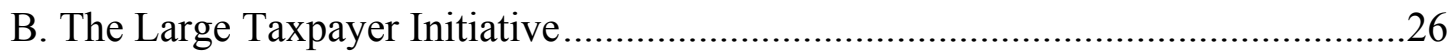

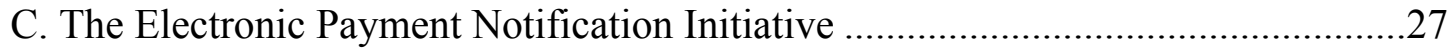

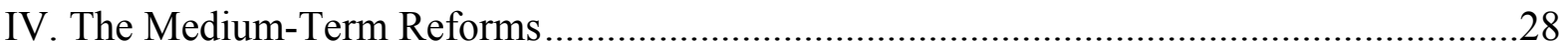

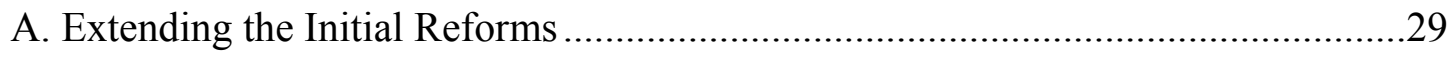

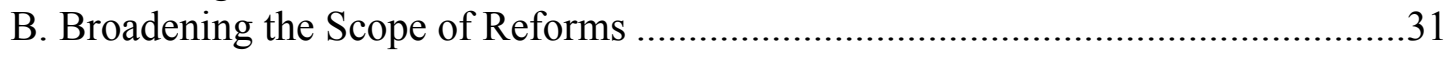

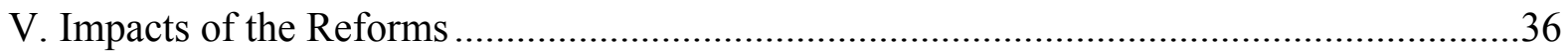

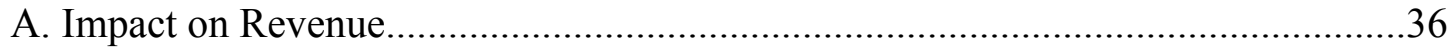

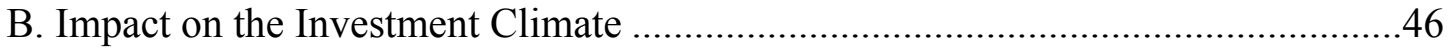

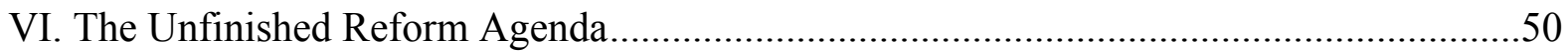

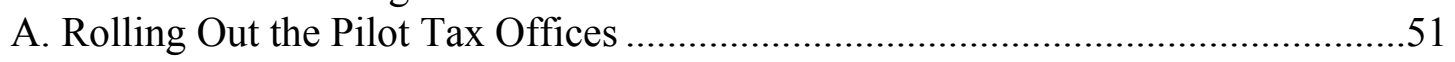

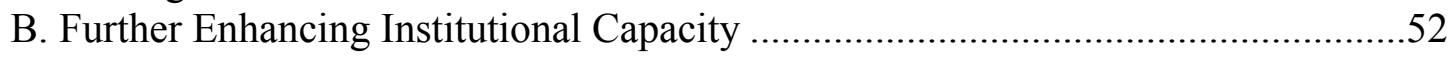

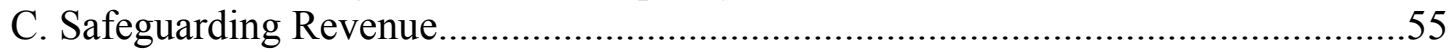

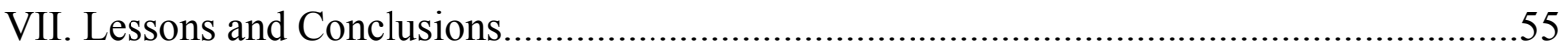

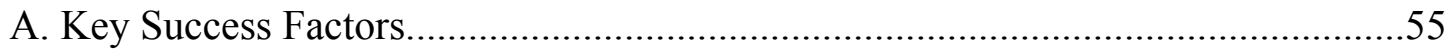

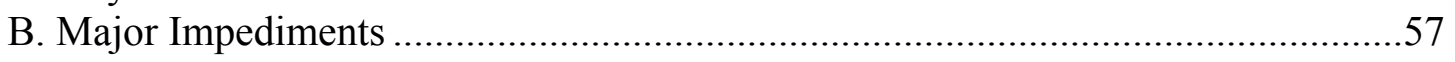

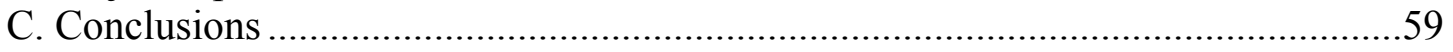

Tables

1. Indonesia: Total Revenue Collections FY1993/94-FY1999/00 ......................................10

2. Level and Composition of Tax Revenue in Selected Asian and Pacific Countries .............11

3. Indonesia: Summary of Central Government Operations, 2000-2006 ............................39

4. Indonesia: VAT Revenue Projections Based on GDP Decomposition, 2000-2006 ...........41

5. Indonesia: Selected DGT Performance Indicators, 2002-2005 .....................................44

6. Indonesia: Sources of the Fiscal Consolidation, 2001-2006 ...........................................45

7. Indonesia: Investment Climate Indicators, 2000-2007 ................................................46 
Figure

1.The Tax Gap and Tax Administration Measures

Box

1. Foundation Statements for the DGT's Medium-Term Plan

Appendices

I. Analytical Framework: Tax Administration and the Tax Yield. .61

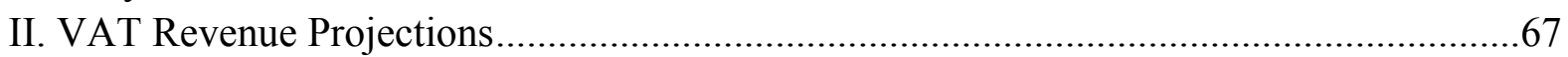

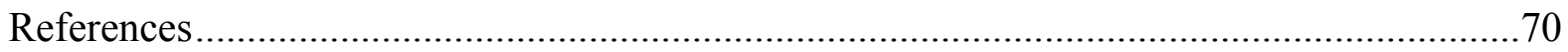




\section{INTRODUCTION}

This paper analyzes the role of tax administration reform in supporting fiscal adjustment based on the recent experiences in Indonesia. The study draws on an extensive set of tax administration reforms that Indonesia's Directorate General of Taxation (DGT) initiated in 2001 and has continued to implement through 2008, with refinements, under the country's broader economic reform program. The paper sets out the key objectives of Indonesia's fiscal adjustment strategy, describes the tax administration reforms that were introduced to help achieve these objectives, and assesses the results of the reforms in terms of both their quality of implementation and impact on the fiscal objectives.

Fiscal adjustment involves the use of public revenue and expenditure measures to help achieve key economic objectives (Daniel et al., 2006). These objectives commonly include promoting economic growth, achieving macroeconomic stability, alleviating poverty, and reducing fiscal vulnerability. Fiscal adjustment has been an integral part of Indonesia's economic reform efforts over the last several years.

A central objective of tax administration is to collect the full amount of taxes due under the tax laws in a cost effective manner and according to a high standard of integrity. In pursuing this objective, tax agencies apply a mixture of measures to help taxpayers comply with the requirements of the tax laws and to enforce compliance when taxpayers fail to do so voluntarily. Both sets of measures have played a role in Indonesia's tax administration reform strategy in recent years.

Tax administration and fiscal adjustment intersect when the implementation of a fiscal adjustment program requires the strengthening of a country's tax agency. In the case of Indonesia, the Indonesian authorities have, over the last several years, viewed the DGT's modernization as being critical to the advancement of two key fiscal objectives:

(1) increasing the tax yield and (2) promoting the investment climate. Indeed, these two objectives have anchored Indonesia's tax administration reforms since 2001.

Against this background, the paper consists of seven sections. Section I describes the broad context for the tax administration reforms in Indonesia. The section reviews Indonesia's macroeconomic situation in 2000 as the country emerged from the Asian financial crisis and describes the key elements of the fiscal adjustment strategy. In addition, the main features of Indonesia's tax regime are described, at the outset of the reforms, including the low tax yield, the complexities in the tax laws, and weaknesses in tax administration.

Section II presents a framework for analyzing the linkages between tax administration and the tax yield, which is elaborated on in mathematical terms in Appendix I. The framework shows that a tax agency collects revenue through two channels: voluntary payments by compliant taxpayers and enforced collections from noncompliant taxpayers. While enforced 
collections may, under some circumstances, provide a potentially large source of tax revenue in the short-term, the framework demonstrates that a tax agency's ability to sustain and increase the tax yield over the medium-term depends critically on expanding voluntary collections by raising taxpayers' compliance rates. This section also provides an overview of the DGT's short and medium-term reform strategies.

Sections III and IV describe the details of the DGT's short- and medium-term reforms, respectively, and review the extent and quality of their implementation. The short-term strategy, which was formulated in late 2001, comprised a small number of initiatives designed to generate quick gains in fiscal adjustment and also to jump-start the process of modernizing the DGT. The medium-term strategy, which was developed in 2003 and refined in subsequent years, provided a more comprehensive set of reforms aimed at addressing the DGT's most fundamental weaknesses. Overall, implementation of the reforms was good although the highly positive results of the short-term reforms are balanced against the more varied progress that has been made in implementing the medium-term strategy (notwithstanding their ongoing nature thanks to the adoption, in 2006, of a new medium-term modernization program backed by senior DGT officials and the minister of finance).

Section $\mathrm{V}$ assesses the impact that the tax administration reforms have had on the key objectives in Indonesia's fiscal adjustment program: increasing tax collection through tax compliance improvements and bettering the investment climate. With respect to the revenue objective, the evidence suggests that the tax administration measures accounted for over half of the 1.1 percentage points of GDP increase in tax collection over the reform period (2002 to 2006, the last year for which actual data is available) - preliminary revenue estimates for 2007 indicate that the good revenue performance is continuing. Regarding the investment climate objective, a number of surveys have indicated that tax administration reforms have had (and continue to have) strong positive effects on investors' perceptions at the pilot tax offices but these necessary but not sufficient reforms need to be (i) broadened to cover a wider range of tax administration issues (in particular the administration's audit and appeals processes); (ii) extended beyond the pilot tax offices; and (iii) sustained over time before they can be expected to have a material impact on the investment climate.

Section VI discusses Indonesia's unfinished reform agenda for tax administration. Despite the good progress that has been achieved since 2001, much work still remains to be done to transform the DGT into a modern and highly effective revenue collection agency. Key reform priorities for the future include: further strengthening the legal framework for tax administration and simplifying the tax system; enhancing the capacity of the DGT's recently reorganized headquarters to manage a national tax administration; refining the strategies for administering different taxpayer segments that have been introduced at the pilot tax offices; continue the modernization of all field offices based on the experiences of the pilot tax offices; introducing a balanced set of performance measures for evaluating core tax administration processes; further develop new human resources management policies that 
create incentives for high performance and noncorrupt behavior among tax officers; and, continuing to improve the DGT's enforcement programs, particularly in the audit area. Reforms in many of these areas have been adopted by the DGT's new management in 2006 and continue to be implemented through today with strong support from the Ministry of Finance.

Finally, Section VII presents the main conclusions that may be drawn from Indonesia's experience with tax administration reform. Some conclusions reaffirm lessons in tax administration reform that the IMF has learned in other countries while other conclusions offer insights into new areas. These include:

- $\quad$ Since 2002, Indonesia's tax administration reforms have been successful in advancing the country's fiscal adjustment program. The improvements in tax administration had (and continue to have) a strong, positive impact on the tax yield and a positive, though difficult to quantify, effect on the investment climate.

- $\quad$ Linking tax administration reform to a government's wider fiscal adjustment program can both assist fiscal adjustment and improve tax administration. Given the gestation period for designing and implementing tax administration reforms, the sooner such reforms can be incorporated into an adjustment program the better.

- Tax administration reform can help raise the tax yield by increasing enforced and voluntary tax collections. Programming these gains should be based on a coherent framework, such as that set out in Section II and Appendix I, with realistic estimates for increasing collections that are linked to concrete administrative measures for bringing about the targeted increases.

- In the short-term, enforced collections may provide a substantial source of additional tax revenue. However, because these collections typically account for a relatively small share of tax revenue, very high growth rates are required to have an appreciable impact on the tax yield. The Indonesian experience demonstrates the practical difficulties of achieving high growth rates in enforced collections year after year.

- $\quad$ Over the medium-term, increasing voluntary collections (by raising taxpayers' compliance rates) is the key way that tax administration can help sustain and expand the tax yield. Therefore, tax agencies should be encouraged to measure tax compliance, identify reasons for noncompliance, and develop appropriate compliance-enhancing strategies.

- $\quad$ Tax administration reform can be a necessary (but not a sufficient) condition for improving a country's investment climate. A tax agency can help boost the investment climate through measures that lower compliance costs faced by taxpayers 
and promote integrity among tax officers. Indonesia achieved promising results in this area through the careful vetting of tax officers, providing sufficiently high salaries, establishing clear standards of conduct that were effectively communicated to taxpayers and tax offices, and accelerating the processing of tax refunds.

- The good results that have been achieved in improving Indonesia's tax administration were due, in part, to a reform strategy that focused initially on a few key initiatives. This approach allowed early successes to be registered in the short-term and helped build confidence within the DGT to take on increasingly more challenging reforms over the medium-term.

- Strong political commitment was critical to the success of Indonesia's tax administration reforms. This commitment was most evidenced by the government's willingness to place tax administration reform high on its reform agenda, allocate resources (staff, budgetary, and technical assistance) to support the reforms, and appoint capable staff to lead the reform effort.

- $\quad$ Technical assistance and policy conditionality can play an important role in helping tax agencies to design and implement reform programs. However, ownership of the reform process by a country's tax agency is indispensable for sustaining the reforms over time.

- There remains ample scope for Indonesia to increase the tax yield and stimulate the investment climate through further improvements in tax administration. In this regard, the strategic plan that the DGT's new management formulated in 2006 provides a sound basis for strengthening revenue collection and promoting fiscal adjustment over the coming years. Preliminary estimates for 2007 revenue collection point to a successful start. 


\section{THE CONTEXT FOR TAX ADMINISTRATION REFORM IN INDONESIA}

Indonesia's fiscal adjustment and tax administration reform strategies emerged in the early 2000's against the backdrop of the East Asian financial crisis. Three factors had a significant role in shaping the tax administration reforms: the macro-fiscal situation, the structure of the tax regime, and the weak state of the DGT's operations.

\section{A. The Macro-Fiscal Situation}

The 1997 Asian financial crisis afflicted Indonesia more severely than most economies and served as a major catalyst for reforming Indonesia's tax administration. Real GDP contracted by 13 percent in 1998, and by July 1998 the Rupiah had depreciated by about 80 percent from the previous year, while inflation had accelerated to about 70 percent per annum. The situation deteriorated further as a run on the banking system left many banks insolvent. While progress had been made in restoring macroeconomic stability by mid-1999, the early gains began to unravel in 2000 and 2001. Slippages in reforms and an increasingly uncertain political climate contributed to renew downward pressure on the Rupiah, and new inflationary pressures emerged.

To achieve economic stability and growth, the Indonesian authorities formulated an economic reform program in 2000 which was supported by IMF financial and technical assistance. The program envisaged restoring the growth rate to 5-6 percent over the medium term, restricting inflation to below 5 percent annually, and achieving fiscal sustainability. Under this program, public debt - which had shot up from 25 percent of GDP before the crisis to about 100 percent of GDP in $2000^{2}$ — was to be reduced to 65 percent of GDP by 2004 .

In this context, the authorities designed a fiscal adjustment program that aimed at achieving a balance between supporting economic recovery and making progress toward the public debt objective. Given the fragility of the emerging recovery in early 2000 , it was considered important to maintain fiscal stimulus in 2000 while planning for early fiscal consolidation. Hence, the government's medium-term macroeconomic framework targeted a gradual reduction in the central government deficit.

With oil production projected to decline, increasing the buoyancy of non-oil and gas tax revenue was to become a key element in Indonesia's fiscal adjustment strategy. ${ }^{3}$ With the

\footnotetext{
${ }^{2}$ The large increase in public debt did not reflect expansionary fiscal policies but rather a large recapitalization of the banking system and a significant exchange rate depreciation.

${ }^{3}$ Another key component of the fiscal adjustment program was a rationalization of spending including through the elimination of untargeted subsidies.
} 
economy slowly recovering from a major economic and financial crisis, the authorities sought to generate as much revenue as possible through improvements in tax administration rather than to rely exclusively or mainly on tax changes for increasing the tax yield (see Tables 1 and 3).

2002 would become a pivotal year for tax administration reform in Indonesia. That year's budget targeted a sizable reduction in the deficit which would require, among other things, increasing non-oil tax revenue by 1.2 percentage point of GDP. About one-half of the revenue increase was to be generated through tax administration improvements. To achieve the targeted increase, the government called upon the DGT to identify specific administrative measures for increasing tax collections. Linking the tax administration reforms to higher order economic objectives would prove crucial for locking in the political commitment needed to implement the DGT's reform agenda.

The government's economic reform program during the early 2000's also attached great importance to improving the investment climate as a key to achieving its growth and employment objectives. With a number of studies and surveys indicating that problems in tax administration were among the top impediments to doing business in Indonesia, tax administration reform came to be seen as crucial for reasons beyond its potential for generating revenue (see Section V.B for details). As a result, the DGT's reform strategy was eventually broadened to include measures aimed at simplifying the compliance requirements of the tax system, promoting integrity among tax officers, accelerating refunds to taxpayers, and a number of other investment-enhancing initiatives.

In this way, the government's macro-fiscal objectives propelled tax administration to a prominent position in Indonesia's economic policy agenda, which triggered a series of tax administration reforms that began in late 2001 and have continued since. Before turning to the details of the tax administration reform strategy, the paper first describes the state of Indonesia's tax system and tax administration in 2000. 
Table 1. Indonesia: Total Revenue Collections FY1993/94-FY1999/00

\begin{tabular}{|c|c|c|c|c|c|c|c|}
\hline & FY93/94 & FY94/95 & FY95/96 & FY96/97 & FY97/98 & FY 98/99 & FY 99/00 \\
\hline & Act. & Act. & Act. & Act. & Act. & Act. & Act. \\
\hline & \multicolumn{7}{|c|}{ (Rp trillions) } \\
\hline Total Revenue and grants & 55.4 & 63.1 & 70.8 & 82.7 & 106.9 & 152.3 & 188.4 \\
\hline Oil and gas revenue & 14.8 & 15.5 & 16.5 & 20.1 & 30.6 & 41.2 & 58.5 \\
\hline Non-oil and gas revenue & 40.2 & 47.1 & 53.8 & 62.0 & 76.3 & 111.0 & 129.9 \\
\hline Tax revenue & 36.7 & 42.7 & 49.2 & 57.2 & 70.0 & 100.7 & 112.8 \\
\hline Directorate General of Taxes & 30.5 & 35.6 & 42.4 & 50.1 & 61.8 & 87.6 & 97.4 \\
\hline Income tax & 14.8 & 18.4 & 21.6 & 27.0 & 34.0 & 55.9 & 59.7 \\
\hline VAT \& luxury sales tax & 13.9 & 15.3 & 18.5 & 20.1 & 24.5 & 27.7 & 33.1 \\
\hline VAT & $\ldots$ & 13.4 & 16.5 & 18.0 & 22.0 & 26.6 & 30.7 \\
\hline Land tax & 1.5 & 1.6 & 1.9 & 2.5 & 2.7 & 3.6 & 4.1 \\
\hline Other taxes & 0.3 & 0.3 & 0.5 & 0.5 & 0.6 & 0.4 & 0.6 \\
\hline Directorate General of Customs & 6.2 & 7.2 & 6.8 & 7.1 & 8.2 & 13.1 & 15.4 \\
\hline Non-tax revenue & 3.5 & 4.3 & 4.5 & 4.9 & 6.3 & 10.3 & 17.1 \\
\hline \multirow[t]{2}{*}{ Grants } & 0.4 & 0.5 & 0.5 & 0.5 & 0.0 & 0.0 & 0.0 \\
\hline & \multicolumn{7}{|c|}{ (percent of GDP) } \\
\hline Total Revenue and grants & 16.3 & 15.8 & 15.1 & 14.9 & 15.4 & 14.9 & 16.6 \\
\hline Oil and gas revenue & 4.4 & 3.9 & 3.5 & 3.6 & 4.4 & 4.0 & 5.2 \\
\hline Non-oil and gas revenue & 11.8 & 11.7 & 11.5 & 11.2 & 11.0 & 10.9 & 11.5 \\
\hline Tax revenue & 10.8 & 10.7 & 10.5 & 10.3 & 10.1 & 9.9 & 9.9 \\
\hline Directorate General of Taxes & 9.0 & 8.9 & 9.0 & 9.0 & 8.9 & 8.6 & 8.6 \\
\hline Income tax & 4.3 & 4.6 & 4.6 & 4.9 & 4.9 & 5.5 & 5.3 \\
\hline VAT \& luxury sales tax & 4.1 & 3.8 & 3.9 & 3.6 & 3.5 & 2.7 & 2.9 \\
\hline VAT & $\ldots$ & 3.3 & 3.5 & 3.2 & 3.2 & 2.6 & 2.7 \\
\hline Land tax & 0.4 & 0.4 & 0.4 & 0.4 & 0.4 & 0.3 & 0.4 \\
\hline Other taxes & 0.1 & 0.1 & 0.1 & 0.1 & 0.1 & 0.0 & 0.1 \\
\hline Directorate General of Customs & 1.8 & 1.8 & 1.5 & 1.3 & 1.2 & 1.3 & 1.4 \\
\hline Non-tax revenue & 1.0 & 1.1 & 1.0 & 0.9 & 0.9 & 1.0 & 1.5 \\
\hline Grants & 0.1 & 0.1 & 0.1 & 0.1 & 0.0 & 0.0 & 0.0 \\
\hline & \multicolumn{7}{|c|}{ (percent of non-oil GDP) } \\
\hline Total Revenue and grants & 18.6 & 18.0 & 17.2 & 17.0 & 17.6 & 17.0 & 18.9 \\
\hline Oil and gas revenue & 5.0 & 4.4 & 4.0 & 4.1 & 5.0 & 4.6 & 5.9 \\
\hline Non-oil and gas revenue & 13.5 & 13.4 & 13.1 & 12.7 & 12.6 & 12.4 & 13.1 \\
\hline Tax revenue & 12.3 & 12.2 & 12.0 & 11.7 & 11.5 & 11.2 & 11.3 \\
\hline Directorate General of Taxes & 10.2 & 10.1 & 10.3 & 10.3 & 10.2 & 9.8 & 9.8 \\
\hline Income tax & 4.9 & 5.2 & 5.2 & 5.5 & 5.6 & 6.2 & 6.0 \\
\hline VAT \& luxury sales tax & 4.7 & 4.3 & 4.5 & 4.1 & 4.0 & 3.1 & 3.3 \\
\hline Land tax & 0.5 & 0.5 & 0.5 & 0.5 & 0.4 & 0.4 & 0.4 \\
\hline Other taxes & 0.1 & 0.1 & 0.1 & 0.1 & 0.1 & 0.0 & 0.1 \\
\hline Directorate General of Customs & 2.1 & 2.0 & 1.7 & 1.5 & 1.4 & 1.5 & 1.5 \\
\hline Non-tax revenue & 1.2 & 1.2 & 1.1 & 1.0 & 1.0 & 1.2 & 1.7 \\
\hline \multirow[t]{2}{*}{ Grants } & 0.1 & 0.1 & 0.1 & 0.1 & 0.0 & 0.0 & 0.0 \\
\hline & \multicolumn{7}{|c|}{ (percent of total revenue and grants) } \\
\hline Total Revenue and grants & 100.0 & 100.0 & 100.0 & 100.0 & 100.0 & 100.0 & 100.0 \\
\hline Oil and gas revenue & 26.7 & 24.6 & 23.4 & 24.4 & 28.6 & 27.1 & 31.0 \\
\hline Non-oil and gas revenue & 72.5 & 74.5 & 75.9 & 75.1 & 71.4 & 72.9 & 69.0 \\
\hline Tax revenue & 66.1 & 67.7 & 69.5 & 69.2 & 65.5 & 66.1 & 59.9 \\
\hline Directorate General of Taxes & 55.0 & 56.3 & 59.9 & 60.6 & 57.8 & 57.5 & 51.7 \\
\hline Income tax & 26.6 & 29.1 & 30.4 & 32.6 & 31.8 & 36.7 & 31.7 \\
\hline VAT \& luxury sales tax & 25.2 & 24.2 & 26.1 & 24.3 & 22.9 & 18.2 & 17.6 \\
\hline Land tax & 2.7 & 2.6 & 2.7 & 3.0 & 2.5 & 2.3 & 2.2 \\
\hline Other taxes & 0.5 & 0.4 & 0.7 & 0.6 & 0.5 & 0.3 & 0.3 \\
\hline Directorate General of Customs & 11.2 & 11.4 & 9.6 & 8.6 & 7.7 & 8.6 & 8.2 \\
\hline Non-tax revenue & 6.4 & 6.8 & 6.4 & 5.9 & 5.9 & 6.8 & 9.1 \\
\hline Grants & 0.8 & 0.8 & 0.7 & 0.6 & 0.0 & 0.0 & 0.0 \\
\hline \multicolumn{8}{|l|}{ Memorandum items } \\
\hline Nominal non-oil GDP (Rp. trillions) & 298 & 351 & 412 & 487 & 608 & 896 & 995 \\
\hline Nominal GDP (Rp. trillions) & 340 & 401 & 469 & 556 & 693 & 1,022 & 1,135 \\
\hline
\end{tabular}




\section{B. The Structure of the Tax System}

Prior to the Asian financial crisis, Indonesia had taken steps to improve the tax system by introducing a modern VAT and income tax. By 2000, the overall design of the tax system was generally regarded as sound, but its yield was low and the tax laws included a number of features that unnecessarily complicated administration. As such, some aspects of the tax policy regime made the challenges of administering the tax system that much greater for the DGT.

The overall yield of the tax system was low. The overall burden of Indonesia's tax system in 2000 was relatively light compared to that of other countries in the region (Table 2). Specifically, the ratio of tax revenue to GDP in Indonesia (excluding oil and gas tax revenues) was 9.9 percent compared to an average of 14.0 percent among non-OECD countries in the region and 24.9 percent among Asian OECD countries. ${ }^{4}$ Indonesia's low tax burden reflected several weaknesses, including the narrowness of major tax bases, relatively low taxation of petroleum, tobacco and certain forms of income, and a high rate of noncompliance among taxpayers. Correcting these weaknesses would be essential to mobilizing the revenue that Indonesia's fiscal adjustment program required.

Table 2. Level and Composition of Tax Revenue in Selected Asian/Pacific Countries /1

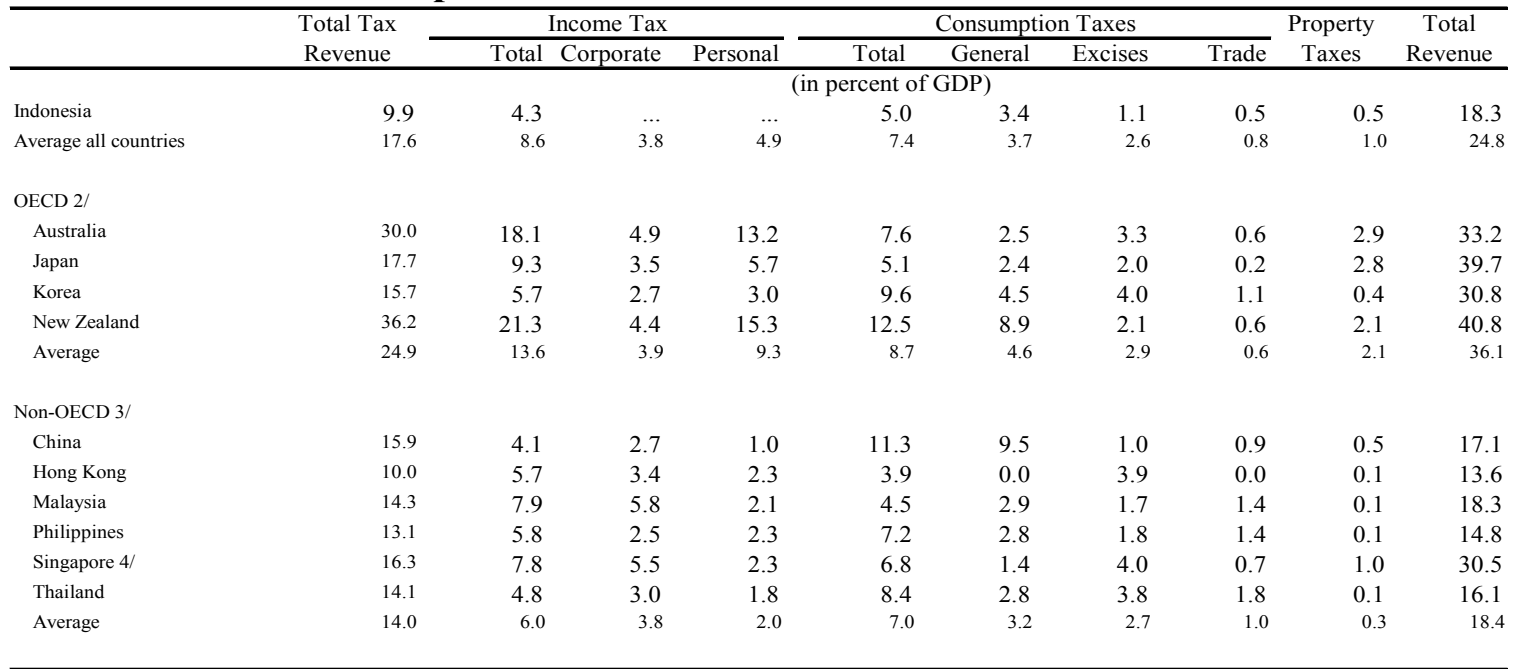

Sources: Revenue Statistics (OECD); OECD Economic Outlook; and IMF country documents

1/ Data from 2001 for either central or general government. Totals do not necessarily add up with their subcomponents as "other taxes" are not shown.

$2 /$ General government

3/ Central government

4/ The breakdown between corporate and personal income tax revenues is estimated to be 70 and 30 percent, respectively.

Income taxes (both corporate and individual) in Indonesia comprised 4.3 percent of GDP (excluding oil and gas income tax revenue) which is noticeably lower than the average of

\footnotetext{
${ }^{4}$ However, thanks to relatively large oil and gas revenue total revenue in Indonesia was similar to other nonOECD countries in the region (18.3 and 18.4 percent of GDP, respectively).
} 
6.0 percent of GDP among selected non-OECD Asian countries. ${ }^{5}$ In these countries, corporate income tax accounts for about two-thirds of total income tax collections and personal income tax the remainder. In Indonesia, because of the means of presenting the data by nature of collection rather than corporate or personal income taxpayers, it is not possible to determine the relevant breakdown. However, a rough allocation of components of income tax revenue (excluding oil and gas revenues) suggests a similar breakdown (or a somewhat lower reliance on personal income tax) as that of non-OECD regional comparators.

General consumption taxes in Indonesia were equivalent to 3.4 percent of GDP compared to the regional average of 3.2 percent for non-OECD comparators. In Indonesia, the general consumption tax category includes VAT and luxury tax, with the latter applying to an extensive list of goods. If the luxury taxes were reclassified to the excise tax category, then the general consumption tax would have yielded about 3.0 percent of GDP, in line with the average for non-OECD regional comparators.

Excise taxes comprised only 1.1 percent of GDP in Indonesia, compared to a regional average of 2.7 percent. The lower share of excises in Indonesia compared to the region was largely accounted for by the omission of petroleum from Indonesia's excise regime. Indonesia does not impose an excise tax or luxury sales tax on gasoline and other petroleum products, which represents a significant source of revenue for many other countries in the region. Excise taxes, both on domestic and international transactions, are collected by Indonesia's customs administration.

International trade taxes. International trade taxes in Indonesia also yielded less than the regional average. This appears to have reflected a combination of weak enforcement, widespread exemptions, and generally low tariff rates.

Property taxes. Property taxes were slightly above the non-OECD regional average. However, compared with OECD countries in the region, this tax yielded little revenue mainly due to its policy design. With a 0.5 percent tax rate and a standard property assessment at 40 percent of market value, the effective rate is 0.2 percent of assessed property value, which is low.

Some features of the tax system were unnecessarily complex. The tax laws included a number of provisions, relating to both income and consumption taxes, that presented difficulties for taxpayers to comply with and for the DGT to enforce. Tax simplification, therefore, offered significant advantages for taxpayers and the DGT alike, and would become a key element in Indonesia's tax administration reform strategy.

\footnotetext{
${ }^{5}$ In Indonesia, income tax revenue from the oil and gas sector is classified as oil and gas revenue instead of tax revenue. In 2001, oil and gas income tax collections is estimated to have been around 1.1 percent of GDP.
} 
Income taxes: ${ }^{6}$ The personal income tax had several positive features that simplified compliance and tax administration, including the widespread withholding of tax at source and a simplified regime for individual entrepreneurs. However, many of these advantages were offset by the government's decision in 2001 to require most individual taxpayers (even employees with only a single source of income) to file an annual tax return. This requirement dramatically increased the number of tax returns that had to be filed beyond the capacity of the DGT to process and enforce.

The corporate income tax law also had a number of features that complicated administration and provided scope for abuse. Chief among these was the reintroduction of tax privileges in 1996 (under Government Regulation 45) which provided tax holidays to newly incorporated firms "operating in certain industries" for up to 10 years. Tax holidays and other tax incentives present serious administrative challenges to a tax agency as they introduce the possibility for taxpayers to transfer profits from operations that do not qualify for the holiday to those that do. Such schemes are also an invitation to corruption as government officials commonly have wide discretion in their administration.

Value-added tax (VAT). ${ }^{7}$ The general design of the VAT in 2000 provided a number of advantages for administration. These included a single positive rate of 10 percent, the limitation of zero-rating to exports, the use of the invoice/credit method (accrual) to calculate the VAT liability, and a simplified regime for small taxpayers. Along with these desirable features, however, the VAT also contained a number of undesirable features that significantly complicated administration. The most serious of these problems involved a legal provision that requires all refund claims to be audited, regardless of the taxpayer's compliance history, prior to payment and approved (or disallowed) within 12 months. ${ }^{8}$ This requirement led to lengthy delays in processing refund claims which caused major cash flow problems for businesses, particularly to exporters who were regularly in a refund position for the value-added tax. It also created problems for tax administration by requiring the DGT to allocate a disproportionate amount of audit resources to examining refund claims and, as a result, leaving insufficient resources for auditing other, potentially more significant issues.

An additional problem involved the VAT-free status of Batam Island, which was difficult to enforce and created risks of significant revenue leakage. Other complications with the VAT involved the separate registration thresholds for goods and services, separate VAT reporting

\footnotetext{
${ }^{6}$ The main income tax legislation is Law No. 17 of 2000, which included provisions applying to both corporate and individual income tax .

${ }^{7}$ Indonesia's VAT is legally defined under Law No. 18 of 2000.

${ }^{8}$ These requirements are stipulated in Article 17 of Law Number 16 (2000) on General Rules and Procedures of Taxation.
} 
by each branch of an enterprise, and the excessive use of "collectors" who were required to withhold 100 percent of the VAT from their suppliers.

Luxury sales tax (LST). The LST added much complexity to the tax system but produced little revenue. The tax provided for approximately 350 tariff codes, which apply to both domestic and imported goods, with more than half of the codes containing either taxable and nontaxable products or products taxable at different rates. The taxable status of a product depended on one of several factors including its price, packaging, quality, or output capacity. Distinguishing among these various factors and applying the correct rate made compliance extremely difficult for the DGT to achieve or verify.

\section{The State of Tax Administration}

In 2000, Indonesia's tax administration was beset by many weaknesses. Poor legal and governance frameworks, shortcomings in organizational and staffing arrangements, ineffective taxpayer services and enforcement programs, and outdated information systems combined to severely reduce the DGT's effectiveness and efficiency in collecting taxes. These weaknesses resulted in large amounts of foregone tax revenue due to noncompliance by taxpayers ${ }^{9}$ and also raised the cost of doing business in Indonesia. Addressing these problems would become central to the DGT's reform strategy and to advancing the government's fiscal adjustment program.

Poor legal and governance frameworks. In Indonesia, the legal framework for tax administration is contained in two sets of laws: the rules that apply to all taxes are set out in the general law on tax administration and arrears collection ${ }^{10}$ while the rules that apply to a particular tax are provided for in each substantive tax law. Deficiencies in this framework meant that tax officers lacked many powers common to modern tax agencies while taxpayers lacked a number of basic protections. From the tax officers' perspective, the deficiencies included a weak penalty regime, inadequate access to taxpayers' records (particularly banking records), and the absence of key powers for enforcing the collection of tax debts. From the taxpayer's perspective, the tax laws led to lengthy delays in processing refunds, did not offer sufficient protection from receiving large (unwritten) arbitrary tax assessments (which often became the basis for negotiating the tax liability), the objection and appeals

\footnotetext{
${ }^{9}$ Statistics from 2000 indicated that 60 percent of corporate taxpayers, accounting for nearly half of turnover, reported no net income while estimates from 2002 revealed that only about 40 percent of potential personal income tax collections was being paid. See Strengthening Tax Policy Through Tax Reform, Indonesia-Japan Economic Working Team, 2004 (pages 15-16).

${ }^{10}$ Specifically, the Law on General Provisions and Tax Procedures (law No. 6 1983) as last amended by law number 16 of 2000 (commonly referred to as the "general law on tax administration") and the Law Concerning Tax Collection with Coerce Warrants as last amended by law number 19 of 2000 (also known as the "law on arrears collection").
} 
processes was viewed as biased in favor of the DGT, and certain tax offences could lead to imprisonment without trial. Together, these problems contributed to an environment of mutual suspicion and distrust between tax officers and taxpayers.

Shortcomings in organizational and staffing arrangements. The DGT's organizational structure suffered from a number of shortcomings. ${ }^{11}$ Headquarters was not organized in a manner that would allow it to effectively manage ongoing operations and develop new tax administration programs. The field offices, on the other hand, had separate units for administering different types of taxes along with a parallel network of audit offices and property tax offices, all of which operated largely independently of each other. ${ }^{12}$ This organizational set up led to a fragmentation of tax administration programs, both at headquarters and the field offices, resulting in a lack of accountability for results.

In addition to its organizational shortcomings, the DGT also had a number of serious staffing problems. During the 1990s and into the 2000s, the DGT had insufficient numbers of staff assigned to the key functions of strategic planning, audit, and taxpayer services. For example, in 1996 the DGT had only about 1,800 skilled auditors, equivalent to about 7 percent of its staff, whereas effective tax administrations commonly assign up to 30 to 40 percent of their staff to the audit function. Such misallocations of staff constrained the DGT in carrying out key management and operational functions.

Ineffective enforcement and taxpayer service programs. In 2000, the DGT had considerable difficulty in enforcing taxpayers' basic obligations under the tax laws: only a very small fraction of the taxpayer population was registered with the DGT and, among those who were, many failed to file their tax returns on time, did not fully pay their tax liabilities, and underreported substantial amounts of taxes. These problems reflected weaknesses in the DGT's enforcement programs, particularly in the audit and arrears collection areas. Similar problems existed in the directorate's taxpayer services function, which was poorly organized, staffed with tax officers who had little training and lacked a service-oriented attitude, and provided taxpayers with only the most basic types of services and assistance.

\footnotetext{
${ }^{11}$ In 1996, the DGT was a three-tiered organization (which included headquarters, regional and field offices) with about 26,300 staff. In addition to a headquarters in Jakarta, the DGT comprised 15 regional tax offices and a network of 303 field offices consisting of 141 district tax offices, 55 audit offices, and 107 property tax offices. This organization was responsible for collecting the following national taxes: income tax applying to corporations $(366,000)$ and individual entrepreneurs $(998,000)$, income tax on wage earners $(9,765,000)$ withheld by their employers (final withholding), value added tax and sales tax on luxury goods $(280,000)$, and property tax ( 75 million properties owned by 40 million taxpayers).

${ }^{12}$ District offices had also separate sections that carried out registration, taxpayer services and debt collection for all taxpayers.
} 
Outdated information technology systems. While the DGT had introduced computer technology to all levels of the organization by the mid-1990s, the quality of its information systems remained very low in 2000 . The main deficiency was that separate, nonintegrated systems were used to administer each tax, thereby making it difficult to get a consolidated picture of taxpayers' overall account status with the DGT. In addition, the information systems provided few automated tools to help front-line staff in carrying out their operational responsibilities and practically no electronic services for taxpayers. Management oversight was severely compromised by the lack of reliable information that could be used to evaluate the effectiveness and efficiency of the DGT's core enforcement and taxpayer services programs.

\section{Summary}

As the government developed its economic reform program in 2000, Indonesia's tax system and its administration suffered from serious weaknesses. Non-oil tax receipts were low, certain features of the tax policy regime were unnecessarily complicated, and tax administration was both weak and arbitrary. At the same time, it was generally recognized that there existed considerable scope (and need) for increasing non-oil tax revenue and promoting the investment climate by improving tax administration. This constellation of factors would bring tax administration reform into sharp focus beginning in late 2001.

\section{The TAX Administration Reform Strategy}

This section describes the tax administration reform strategy that the Directorate General of Taxation (DGT) formulated beginning in late 2001 and has continued to implement, with refinements and additions along the way, ever since. The section begins by presenting a framework for analyzing the revenue impact of tax administration reform, and then provides an overview of DGT's short-term and medium-term reforms, which are elaborated on in Sections III and IV, respectively.

\section{A. Analytical Framework}

In designing tax administration reform strategies where increasing revenue is a key objective, it is important to understand the linkages between a tax agency's administrative programs and the tax yield. These linkages are described conceptually below and expressed more precisely in mathematical terms in Appendix I.

The "Tax Gap" concept. The analysis of how tax administration improvements can increase tax revenue is anchored in the concept of the tax gap. The tax gap is generally defined as the difference between, on the one hand, the amount of tax revenue that would have been collected had all taxpayers fully complied with their obligations under the tax laws and, on the other hand, the amount of tax revenue that was actually collected by the tax 
administration. The difference, or gap, between potential and actual tax collections consists of taxes that were legally due but not paid by taxpayers as a result of noncompliance. ${ }^{13}$

The tax gap has three main components: nonfiling, underreporting, and underpayment. The nonfiling gap represents the amount of taxes not paid by taxpayers who have an obligation to file a tax return, but do not file on time. The underreporting gap is the tax owed by taxpayers who file tax returns on time, but do not report the full amount of tax they owe. The underpayment gap is the amount of foregone revenue resulting from taxpayers who fail to fully pay on time the amount of tax owed.

The tax gap provides a useful organizing principle for designing a tax administration reform strategy within the context of a fiscal adjustment program. A tax agency has at its disposal various measures to increase actual tax collections relative to potential collections and, thereby, reduce the tax gap. Before turning to these measures it is important to first recognize that tax collections take two broad forms.

Forms of tax collection. A tax agency receives revenue in two ways: (i) taxes that are paid voluntarily by taxpayers and (ii) taxes that are collected from noncompliance taxpayers through some form of enforcement by the tax authorities. In all countries, these two forms of collection account for vastly different shares of tax revenue and respond differently to a tax agency's administrative programs.

Voluntary collections. Voluntary collections consist of those taxes that are paid by taxpayers without requiring any direct form of enforcement on the part of the tax authorities. These collections commonly occur when taxpayers self-assess a tax return and voluntarily pay the declared tax liability. In all countries, voluntary collections account for a much larger proportion of tax revenue (usually far more than 90 percent) than enforced collections. A tax administration can increase voluntary collections by putting in place measures that raise the rate of voluntary compliance among taxpayers. ${ }^{14}$

Because of the large share of voluntary collections in tax revenue, relatively small increases in taxpayers' compliance rates can generate substantial increases in tax revenue. However, it may take time for a tax agency's measures to increase voluntary collections since these measures work through changes in taxpayers' compliance rates which often take a while to adjust. The difficulties in measuring compliance rates is one of the reasons why fiscal

\footnotetext{
${ }^{13}$ The tax gap can be measured on both a gross and net basis. The gross tax gap equals the difference between potential and actual tax collections. The net tax gap equals the gross tax gap in any particular year less any tax revenue that the tax agency recovers through enforcement (See Toder, 2007).

${ }^{14}$ The rate of voluntary compliance is defined as the ratio of voluntary collections to potential collections.
} 
analysts are often reluctant to program tax administration gains into their revenue projections.

Enforced collections. Enforced collections are those taxes that a tax agency collects through some form of enforcement action that is taken against noncompliant individuals and businesses. Examples include revenue recovered from taxpayers who failed to file a tax return on time, underreported their taxes, or owed tax arrears. Revenue from enforced collections normally accounts for a relatively small share of a country's tax revenue (commonly far less than 10 percent).

Because of its small share in total tax collections, enforced collections must increase at a high rate in order to have a significant impact on the tax yield. Nevertheless, enforced collections have the potential to increase quickly, since these collections do not require adjustments in taxpayers' compliance patterns, but instead result directly from a tax agency's own enforcement actions. Since most tax agency's have the capacity to measure the amount of revenue recovered through enforcement, fiscal analysts can estimate more precisely the potential for tax administration measures to increase enforced collections than voluntary collections.

Tax administration instruments and their linkages to the tax yield. A tax agency has two broad sets of instruments for reducing the tax gap: compliance facilitation and compliance enforcement. These two sets of instruments affect the tax yield in different ways through their impacts on voluntary collections and enforced collections.

\section{Compliance facilitation affects the tax yield by increasing voluntary collections.}

Compliance facilitation entails those tax administration measures that make it easier for taxpayers to comply with their obligations under the tax laws. Common examples include simplifying the tax laws, streamlining administrative procedures and information reporting requirements, and improving taxpayer services. By reducing the cost of compliance, compliance facilitation creates incentives for taxpayers to voluntarily pay their taxes. To the extent that taxpayers respond positively to these incentives, their voluntary compliance rate will increase and voluntary collections will rise.

\section{Compliance enforcement affects the tax yield by increasing both voluntary collections and enforced collections. Compliance enforcement involves a tax agency's measures for detecting and redressing noncompliance by taxpayers. Common examples include identifying potential registrants, detecting underreported tax liabilities, and recovering delinquent tax returns and late tax payments. Compliance enforcement measures can have a direct effect on the tax yield by increasing enforced collections. They can also have an indirect effect on the}


tax revenue by discouraging taxpayers from engaging in noncompliance and thereby increasing voluntary collections. ${ }^{15}$

To summarize the discussion, Figure 1 below illustrates how the various concepts fit together. As can be seen in the diagram, potential tax collections represent the amount of revenue that would have been collected had taxpayers fully complied with the tax laws. Actual tax collections equal the amount of taxes that taxpayers paid voluntarily plus the amount of taxes that a tax agency recovered through some form of enforcement. The gross tax gap equals the difference between potential tax collections and voluntary tax collections while the net tax gap equals the gross tax gap less the amount of enforced collections. A tax agency can reduce the tax gap (and, thereby, increase the tax yield) through compliance enforcement measures (which can increase both enforced and voluntary collections) and compliance facilitation measures (which can increase voluntary collections).

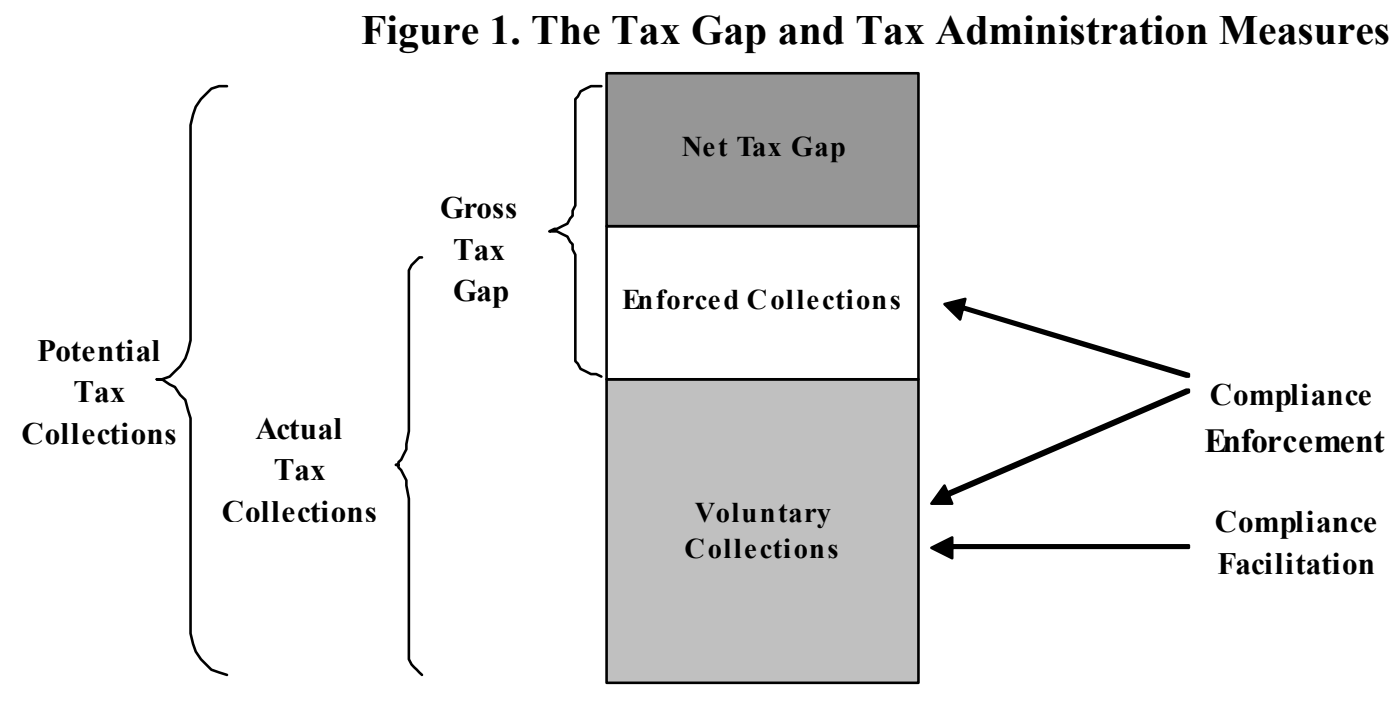

\section{B. Overview of the Reform Strategy}

Indonesia's tax administration reforms were guided by two primary objectives in the fiscal adjustment strategy: increasing the tax yield and promoting the investment climate. In pursuing these objectives, the DGT formulated both short- and medium-term reform strategies whose main features and their rationale are summarized below.

\footnotetext{
${ }^{15}$ For example, economists have estimated that in the United States, the audit program's indirect effects on voluntary collections are from 6 to 12 times greater than the audit program's direct effects on enforced collections. See Plumley (1996), Dubin et.al. (1990), and Dubin (2004).
} 


\section{The short-term reforms}

In late 2001, the DGT developed a short-term reform strategy in close coordination with the MOF which, at the time, was formulating the country's fiscal adjustment program. In designing the short-term strategy, priority was given to those tax administration measures that could have an immediate impact on both the tax yield and the investment climate as well as jump-start the process of modernizing the DGT. The latter was seen as crucial for further increasing tax collection and improving the investment climate over the medium-term.

The scope of the short-term strategy was constrained by the DGT's limited implementation capacity. At the time, the DGT had little experience in managing a comprehensive reform program and had little time to produce results. Consequently, the short-term strategy was restricted to a small number of reforms that the DGT could effectively manage and which could generate quick results. This approach of focusing on a few major initiatives and piloting their implementation wherever possible has been a constant theme in Indonesia's tax administration reform strategy since 2001.

The DGT's short-term strategy was built around three initiatives: (i) a "revenue generation program" which included a number of measures aimed at tightening the enforcement of the tax laws. The rationale for this initiative flowed from the analytical framework that was presented in the previous subsection which demonstrated that stepped-up enforcement could yield potentially large increases in tax revenue in the short-term; (ii) the establishment of a special tax office within the DGT to administer the largest taxpayers. Since these businesses were not only large taxpayers but also large investors, it was felt that this initiative could have significant short-term impacts on both tax revenue and the investment climate; and, (iii) the introduction of an electronic system for processing tax payments to replace the existing system, which was slow, costly, and vulnerable to "leakage." This initiative, which was already on the drawing board in 2001, could enhance tax collections by accelerating the processing of tax payments and guarding against illicit paper-based payment advices, a common problem at the time.

\section{The medium-term reforms}

As the short-term reforms were being implemented during 2001 and 2002, it became apparent that a broader set of tax administration reforms would be required to further increase tax collections and promote the business climate over the medium-term. To achieve these goals, the DGT would have to address its most fundamental weaknesses, including those involving the legal and governance frameworks for tax administration, organizational and staffing arrangements, taxpayer services and enforcement programs, information systems and technologies, and human resource management policies. Given the deep-seated nature of these problems, a medium-term perspective was needed for their improvement. 
In early 2003, the DGT designed a medium-term reform plan, which was intended to be implemented over the next three years. In broad terms, the plan provided for a continuation of the short-term strategy and added to these reforms several major new initiatives. More specifically, the medium-term plan comprised the foundation statements in Box 1 and the following ten initiatives:

(1) Increasing the number of taxpayers administered by the large taxpayer office (LTO) and extending the LTO reforms to another region that also administered large businesses.

(2) Establishing model tax offices for administering small and medium-sized taxpayers, and gradually extending these models to all tax offices throughout Indonesia.

(3) Continuing the revenue generation initiative.

(4) Simplifying each major tax, beginning with the value-added tax.

(5) Revising the legal framework for tax administration.

(6) Enhancing the capacity of the DGT's audit function.

(7) Developing a balanced set of performance measures for the DGT's core tax administration processes.

(8) Introducing new human resource management policies.

(9) Designing a comprehensive information technology master plan.

(10) Creating an internal investigation unit to investigate misconduct by tax officers.

Although the medium-term plan would be refined in subsequent years to include additional measures - such as reorganizing DGT headquarters and creating data processing centersthe ten above-mentioned initiatives would continue to form the core of the reform strategy through 2007. 


\section{Box 1. Foundation Statements for the DGT's Medium-Term Plan}

Mission Statement: To collect the full amount of revenue required under the tax laws at a minimum cost to taxpayers and the government.

Vision Statement: By 2006, the Directorate General of Taxation will become the premier tax administration among developing countries in Asia and a leading institution in Indonesia's public service in terms of taxpayers' compliance with the laws, excellence in service to taxpayers, fairness and integrity in tax administration, and the quality of the work environment for tax officials.

\section{Guiding Principles:}

Simplicity. The tax system and its administration should be easy to comply with.

Predictability. Tax laws and regulations should be clear, accessible, and consistently applied.

Effectiveness. Taxpayer services and enforcement programs should be tailored to the specific characteristics of large, medium, and small taxpayers.

Integrity. The DGT should adopt a policy of "zero-tolerance" for corruption.

Performance. There should be incentives for high performance and accountability for results.

Transparency. Actions taken by the tax administration should be subject to scrutiny and results widely publicized.

Efficiency. Paper-based processes should be eliminated through extensive investment in modern technologies.

Quality. Problems should be identified and resolved before they become disputes.

Fairness. Dispute resolution mechanisms should be fast, low-cost, and impartial.

Professionalism. Tax officers should be competent and highly motivated.

Goals:

1. High level of taxpayers' compliance with the tax laws

2. High level of taxpayers' confidence in tax administration

3. High level of efficiency in administration

\section{THE SHORT-TERM REFORMS}

The DGT launched its tax administration reform strategy in 2001 with an initial set of reforms that was intended to be implemented over the next 12-18 months. The main driving force behind the short-term strategy was the government's 2002 budget which set a target of increasing tax revenue by 0.5 percentage points of GDP through improvements in tax 
administration. The strategy was also driven by the government's desire to begin removing the impediments to the investment climate, including those related to tax administration.

In this context, the DGT selected three main initiatives to start the reform process: (i) several enforcement measures which were collectively known as the revenue generation initiative; (ii) the creation of a special tax office for administering large taxpayers; and (iii) the introduction of an electronic payment notification system. As will be seen, these initiatives were successfully implemented in almost all aspects and had a positive impact in advancing the government's fiscal adjustment program. They also created within the DGT a momentum for change that would later help to spawn a broader reform program over the medium-term.

\section{A. The Revenue Generation Initiative}

To help achieve the revenue target in the 2002 budget, the DGT implemented four measures aimed at intensifying enforcement: (i) registering additional taxpayers (the "extensification" program); (ii) improving audit performance; (iii) intensifying the collection of tax arrears; and, (iv) enforcing tax return filing requirements. These measures were expected to generate short-term revenue gains mainly by increasing enforced collections. Over the medium-term, the reforms were also expected to increase voluntary collections as taxpayers gradually improved their compliance rates in response to the DGT's stepped-up enforcement efforts.

While each of the four enforcement programs had its own distinct features, all four shared a common approach that included the preparation of an annual plan that set targets for the number and types of enforcement actions that were to be undertaken. The plans also included a forecast for the amount of taxes that each enforcement program was expected to generate. The comparison of the actual and estimated amounts of enforced collections provided the authorities with a convenient (but partial) way for measuring the revenue impact of the tax administration reforms. ${ }^{16}$ This has important implications for designing fiscal adjustment programs as it demonstrates that the revenue impact for at least some tax administration measures can be measured fairly easily.

The extensification program. This program aimed at identifying and registering those individuals and businesses that were carrying out taxable activities without having registered for taxation with the DGT. Given the large number of businesses and individuals who were thought to be operating outside the tax system, the extensification program was considered fertile ground for expanding the tax net and increasing revenue.

\footnotetext{
${ }^{16}$ Increases in enforced collections captures only the direct effects that tax administration can have on the tax yield. It excludes the potentially large indirect effects that tax administration reform can have on the tax yield by increasing voluntary collections. Section VI provides a fuller analysis of the effects that Indonesia's tax administration reforms have had on the tax yield.
} 
To expand the tax net, the DGT focused on registering high-income earners (both companies and individuals) and securing their future compliance with the tax laws. Specific actions for identifying potential registrants included: (i) exploiting third-party information to identify owners of luxury cars and expensive homes, professional service providers, and other indicators of tax potential; (ii) canvassing shopping malls, newspapers, and the Internet to ensure that all businesses were registered; (iii) an aggressive advertising campaign to promote tax registration through television and billboards; (iv) implementation of an electronic registration system which allowed taxpayers to register over the Internet; and, (v) sending letters to new registrants to remind them of their obligation to file an income tax return.

The extensification program was highly successful in registering large numbers of taxpayers. More than 11 million new taxpayers were registered from 2002 to 2005 . However, while searching for high-income registrants, large numbers of low-income taxpayers were also registered. Consequently, while the amount of tax collections that was generated by the extensification program rose steadily from Rp. 0.5 trillion in 2002 to Rp. 2.1 trillion in 2005 , many of the new registrants contributed little revenue but added significantly to the DGT's administrative costs. From a revenue perspective, future registration efforts would be well advised to focus on registering medium-sized businesses (since it is highly unlikely that large scale businesses are operating outside the tax net) and higher wealth individuals.

The audit program. The purpose of this program was to increase the DGT's capacity to identify and tax unreported income and sales. By doing so, an intensified audit program was seen as providing a ready source of additional tax revenue, first by recovering underreported taxes (and, hence increasing enforced collections) and second by improving taxpayers' compliance rates (and, thereby, increasing voluntary collections).

The DGT identified five major reforms for strengthening its audit function: (1) a national audit plan that sets targets for the number and types of audits to be conducted by each field office for different categories of taxpayers and economic sectors; (2) increasing audit coverage for large and medium-sized businesses; (3) reducing the excessive amount of audit resources that was allocated to examining refund claims, regardless of the claimants' compliance histories; (4) improving case selection systems by developing computer-based algorithms that would target audits on those taxpayers who had the highest risk of underreporting taxes; and, (5) developing management reporting systems that would help DGT headquarters to better monitor the audit activities of the field offices. The strategy purposely excluded improving the methods and techniques that auditors use in examining taxpayers' records, which, while critical, could only be implemented over the medium-term because of their extensive training requirements.

Although the results varied among the five audit reforms, the audit program as a whole was successful in recovering substantial amounts of revenue. The initiative generated 
Rp. 3.2 trillion in tax collections in 2002 which more than doubled over the next three years, reaching Rp. 7.8 trillion in 2005. Notwithstanding the impressive revenue results, the continuing weaknesses in key aspects of the DGT's audit program - most notably, in case selection, third-party data matching, and the methods used by auditors to examine taxpayers' records - means that this remains an area with substantial, unrealized revenue potential.

The arrears collection program. This program sought to enhance the DGT's ability to recover taxes that were legally due but had not been paid by taxpayers within the statutory payment deadline. In 2001, the stock of tax arrears stood at about Rp. 17 trillion which was equivalent to about 13 percent of tax collections for that year. Although this was not excessive by regional standards, tax arrears nevertheless represented another source of potential revenue to support the fiscal adjustment program's revenue objective. ${ }^{17}$

To intensify arrears collection, the DGT implemented the following four measures:

(i) immediate assignment of new tax arrears cases to collection officers for action; (ii) the close monitoring of the largest 1,000 debt cases; (iii) increased use of existing legal provisions to freeze tax debtors' bank accounts; and, (iv) publicizing the names of tax debtors. These measures could be implemented relatively quickly, as they did not require changes in legislation or significant re-training of staff, and, therefore, could have an immediate impact on revenue.

Despite limitations with some of the measures, the arrears collection program generated more revenue than was originally expected. Under this program, the DGT recovered Rp. 4.8 trillion in tax arrears in 2002. Over the next three years, the recovery of tax arrears more than doubled, reaching Rp. 10.5 trillion in 2005. With the stock of tax arrears has continued to rise in recent years - as a result of the increase in the DGT's audit activities and the associated increase in audit assessments - the collection of delinquent taxes continues to be a good source of additional revenue.

The returns filing enforcement program. This program sought to improve taxpayers' compliance with their obligation to file tax returns. In 2001, filing compliance was extremely poor: only about one-third of registered businesses and one-quarter registered of individuals filed an income tax return despite the obligation to do so. This problem was a matter of serious concern as noncompliance with filing obligations not only results in a loss of revenue but also strikes at the very heart of the tax system: in an environment where there are few consequences for failing to file a tax return, compliant taxpayers are also encouraged to opt out of the tax system.

\footnotetext{
${ }^{17}$ By comparison, in 2001 tax arrears as a percent of tax collections was 15.5 percent in Thailand and 20 percent in the Philippines.
} 
To improve filing compliance, the DGT developed an action plan in 2003 that included increasing the penalty for late filing, introducing systematic procedures for following-up on nonfilers, establishing a special team of tax officers to issue estimated (default) assessments to nonfilers, and commencing prosecution of certain high profile nonfiler cases. Implementing this plan would require the issuance of several important decrees.

The results of this program were disappointing. Delays in promulgating the required decrees meant that little progress was made in implementing the reforms and, as a consequence, little revenue was generated. With taxpayers' filing rates are still very low, the initiative retains the potential for generating substantial tax revenue in the future.

\section{B. The Large Taxpayer Initiative}

This initiative involved the creation of a special large taxpayer office (LTO) within the DGT to administer the relatively small number of taxpayers who collectively accounted for the largest portion of tax collections. The LTO opened in July 2002 at which time it administered 200 large enterprises and their 300 branches who contributed 23 percent of total tax collections. In 2004, the LTO was expanded by an additional 100 large corporations, which brought LTO tax receipts up to 27 percent of total DGT collections.

The large taxpayer initiative offered important advantages for Indonesia's fiscal adjustment program through its potential for: (1) increasing tax revenue by achieving tight control over a large portion of the tax base and (2) improving the investment climate by providing large taxpayers, who were also large investors, with high quality services and introducing a number of measures to curb malfeasance by tax officers. In addition, the creation of an LTO was viewed as an important stepping stone in modernizing the DGT by providing a controlled environment for testing a wide range of new tax administration processes prior to their roll-out to other tax offices.

The LTO initiative encompassed several major reforms. The LTO was re-organized into units based on tax administration function (e.g., taxpayer services, audit, arrears collection), which facilitated the development of specialized skills among staff. Service to large businesses was improved through the creation of a cadre of service-oriented tax officers who were trained in the complex tax law issues that often arise when dealing with large taxpayers. ${ }^{18}$ Refunds were accelerated through the introduction of a "gold-card" program

\footnotetext{
${ }^{18}$ A key feature of the LTO's taxpayer services function was the assignment of an "account representative" (AR) officer to each large taxpayer. For his assigned set of large taxpayers, the AR served as the first point of contact into the LTO for answering questions on the tax law, straightening out problems involving a taxpayer's account with the DGT, and following up on such issues as delays in issuing refunds. The AR also closely monitored the taxpayer's filing and payment obligations, and was authorized to undertake some initial enforcement actions such as calling a taxpayer who filed a late tax return or did not pay tax on time.
} 
which simplified the refund process for highly compliant businesses. Enforcement was strengthened through the quick identification and rapid treatment of taxpayers who filed their tax returns late, paid their taxes late, or committed other forms of noncompliance. Perhaps most notably, the LTO provided for a careful vetting of staff, substantially higher wages, a widely publicized code of conduct, and improved IT systems and office facilities. This quality work environment was crucial in promoting productivity and noncorrupt behavior among LTO staff.

The LTO reforms were well implemented and produced excellent results. As described in section VI, the growth rate of LTO tax collections substantially exceeded that for the rest of the DGT. At the same time, large taxpayers reported a high degree of satisfaction with the LTO's services, the integrity of its staff, and the measures taken to accelerate refunds. Importantly, the new tax administration features that were introduced at the LTO would later become the standard for the DGT and were gradually rolled-out to additional field offices.

\section{The Electronic Payment Notification Initiative}

This initiative involved replacing the existing paper-based system for processing tax payments and tax refunds with a modern, electronic system. By allowing tax payments to be processed more quickly and reliably, the electronic system had advantages for the DGT and taxpayers alike. As such, the initiative had the potential for improving both tax collection and the investment climate.

The payment system that had been in place in 2001 was slow, costly, and vulnerable to abuse. The paper-based nature of the system resulted in significant time delays before the DGT received confirmation of a tax payment from Directorate General of Budget, which seriously hampered the DGT's capacity to identify delinquent taxpayers on a timely basis and take action to recover tax arrears. The paper-based payment system also created opportunities for unscrupulous taxpayers to submit fake payment advices to the DGT and receive credit for taxes that they had not actually paid.

With the new electronic system, banks, upon receipt of a tax payment from a taxpayer, sent an electronic payment advice to the DGT which was automatically posted to the taxpayer's account with the DGT. The payment information was conveyed over a secure communication line linking the banks to the DGT, and included a number of controls that ensured the authenticity of the payment. Through this system, the DGT received real-time notification of a tax payment from banks.

The new payment system was piloted at the LTO in 2002 and by 2003 was processing nearly 90 percent of the tax payments received by the DGT. Though difficult to measure, the system had positive effects on both revenue collection and the investment climate. By speeding up the flow and accuracy of tax payment information, the new system helped to increase tax 
revenue as it virtually eliminated fake payment advices and allowed tax officers to take timely action against those taxpayers who failed to pay their taxes on time. The system also helped improve the business climate by restoring taxpayers' trust in the tax payment system: prior to the introduction of the electronic system, it was purportedly not uncommon for taxpayers to be presented with payment demands for tax liabilities that they had already paid.

\section{Summary}

The short-term reform strategy was highly successful in strengthening tax administration. In almost all cases, the short-term reforms were implemented in line with good international practice and achieved a high quality of implementation. The key success factors explaining the good results appear to be that the strategy, while limited in scope, focused on those reforms that were both critical to the fiscal adjustment program and within the DGT's limited implementation capacity. This approach allowed the reforms to be implemented rapidly and the results to be realized quickly. Yet the short-term reform strategy had its limitations: sustaining and further improving the initial results over the medium-term would require a broader and more complex set of reforms, as discussed in the next section.

\section{ThE MEDIUM-TERM REFORMS}

Building on the positive results that had been achieved by the short-term reforms in 2001 and 2002, the DGT took a decision in 2003 to develop a more ambitious set of reforms that aimed at sustaining and further advancing Indonesia's fiscal adjustment program over the medium-term. As the new strategy was being developed, the central objectives of the fiscal adjustment program remained unchanged: achieve fiscal sustainability and promote the investment climate. However, the authorities recognized that a more intensified and broader set of tax administration reforms would be needed to help achieve these objectives over the medium-term.

The DGT's medium-term reform strategy followed a two-tracked approach of: (1) gradually extending the short-term reforms while (2) broadening the scope of reforms to address the tax agency's most fundamental weaknesses. As such, the medium-term strategy included 10 major initiatives, which cut across a wide range of topics, including new legislation, tax administration processes, and information systems. The DGT introduced the strategy during the second half of 2003 and continued to implement the reforms, at varying degrees of intensity and with some refinements, through 2007.

In contrast with the short-term reforms, the quality of implementation for the medium-term reforms was more varied: some initiatives were implemented on time and as intended while others were not. These mixed results reflected a number of factors, including the inherent complexity of the reforms and a pause in the reform effort following the election of a new government in 2004 — which wanted to take stock of the existing administrative reforms; the 
reform drive started anew with the election of a successor government in December 2005. Despite the mixed results, the medium-term reform strategy has still delivered important gains and established the broad direction for the DGT's ongoing reform efforts.

\section{A. Extending the Initial Reforms}

Rolling out the large taxpayer reforms. By 2003, some of the innovations that had been successfully introduced at the LTO were reaching a level of maturity that signaled their readiness for extension to other tax offices. Accordingly, the DGT took a decision in early 2003 to commence the roll-out of the large taxpayer reforms to its administrative Region VII in Jakarta. This region had a number of similarities with the LTO-including significant numbers of large taxpayers and large investors - which made it an ideal candidate for adopting the large taxpayer reforms. ${ }^{19}$

Planning for the roll-out started in late 2003. By the end of 2004, the LTO reforms had been fully implemented at all of the tax offices in Region VII. These reforms included:

(i) reorganization of staff into units based on tax administration function; (ii) merging of the field offices and audit offices; (iii) the appointment of staff based on merit; (iv) enhanced taxpayer services, including the assignment of an account representative to each large taxpayer; (v) more effective enforcement procedures; (vi) introduction of higher salary packages linked to a new code of conduct; and, (vii) refurbishment of office accommodations.

The extension of the LTO reforms to Region VII by end-2004 produced excellent results. The reforms were carefully planned and smoothly implemented. They led to significant increases in tax revenue and overwhelmingly favorable feedback from taxpayers, as described in section VI. As such, the Region VII initiative had a highly positive impact on the fiscal adjustment program and continued to be a key reform driver through 2007.

Improving the administration of small and medium-sized taxpayers. Having established effective arrangements for large taxpayers, the DGT turned its attention to developing new approaches for administering other categories of taxpayers. This initiative aimed at tailoring the DGT's taxpayer services and enforcement programs to the characteristics of small and medium-sized taxpayers. The reforms were to be tested in one region and, if successful, replicated throughout the country.

\footnotetext{
${ }^{19}$ Region VII comprised about 1,050 staff across one regional office, 8 field offices, and 2 audit offices. These offices were responsible for administering about 15,000 companies and 2,500 individuals who accounted for about 22 percent of DGT collections. The companies include state-owned companies, local government enterprises, enterprises with foreign investment, foreign-owned companies and foreign resident individuals, and domestic public companies.
} 
The DGT's Jakarta Region VI was chosen as the pilot region for designing and testing the reforms. In early 2005, the region created two special tax offices: a Medium Taxpayer Office (MTO) to administer the region's 200 largest taxpayers and a Small Taxpayer Office (STO) for businesses with small amounts of turnover. Although the STO and MTO were originally envisaged to customize their operations for small and medium taxpayers, in actuality the offices mainly implemented the more generic reforms that had been introduced for large taxpayers, with some modifications. These reforms included re-organizing the offices into units based on tax administration function, increasing staff salaries, enhancing communications with taxpayers, and introducing modern technology and improved office accommodations.

By the end of 2007, the MTO and STO had achieved highly positive results in terms of improving compliance, revenue collection, and taxpayer satisfaction which are evaluated in section VI. However, the positive results were more attributable to the general modernization of the tax offices than to the customization of the DGT's administrative programs for small and medium-taxpayers. Thus, realizing the full potential of the small and medium taxpayer reforms will depend not only on rolling-out the generic reforms to additional tax offices ${ }^{20}$ but $^{2}$ more importantly to better tailor the DGT's enforcement and taxpayer services to the requirements of small and medium-sized taxpayers. Such tailored approaches could include simplified bookkeeping methods, volunteer tax return preparers, centralized processing of tax returns, telephone contact centers, industry-specific audit guides, and indirect audit methods for examining taxpayers with inadequate books and records.

Continuing the revenue generation initiative. While the medium-term reforms were being designed and implemented, the DGT recognized the continuing importance of protecting ongoing tax collections. For this reason, a decision was taken to continue the revenue generation initiative, which had been first introduced in 2002. As was described in the previous section, this initiative entailed the setting of national targets for each of the DGT's main enforcement programs (e.g., number of new taxpayers to be registered, number of audits to be completed, amount of arrears to be recovered) and the implementation of specific measures to achieve the targets.

Through 2005, the revenue generation initiative continued to generate substantial amounts of revenue and, as such, had a positive impact on the fiscal adjustment program's revenue objective. The initiative demonstrated that good revenue results could be achieved simply by establishing reasonable targets for key enforcement programs and holding staff accountable for their achievement. Unfortunately, the DGT discontinued the systematic tracking of tax collections from each of its four major programs after 2005.

\footnotetext{
${ }^{20}$ As of December 2007, the DGT had established a total of 19 MTO's and 171 STO's.
} 


\section{B. Broadening the Scope of Reforms}

As the medium-term reforms were being formulated, the DGT recognized that further increases in revenue collection and improvements in the investment climate would require more than just extending the initial tax administration reforms to additional tax offices. With this in mind, the medium-term strategy also included a broader set of reforms aimed at addressing some of the most fundamental constraints to the DGT's performance.

Simplifying the tax laws. This initiative envisaged conducting a comprehensive review of each major tax, beginning with the value-added tax (VAT), with a view towards identifying and eliminating those aspects of the tax system that unnecessarily raised the costs of compliance and administration. Tax simplification was expected to advance the fiscal adjustment strategy by: (1) increasing tax revenue through the facilitation of voluntary compliance and (2) improving the investment climate by reducing the complexities and uncertainties that the tax system posed for investors.

The initiative began with the appointment of a joint public sector-private sector Task Force on VAT Simplification in May 2003, which submitted its final report and recommendations to the Minister of Finance in December of that year. The report resulted in the adoption of a number of important reforms, the most important of which was the extension of the "gold card" program beyond large taxpayers. This program accelerated the processing of VAT refund claims, normally within seven days, for highly compliant taxpayers. Other reforms included unifying and raising the VAT registration threshold for goods and services, and restricting the number of VAT withholding agents to government treasuries.

Notwithstanding the improvements that were introduced to the VAT in 2003, many other measures that have a high potential for simplifying the VAT have not been adopted. These include: (1) eliminating the requirement for auditing all refund claims; (2) substantially reducing the numerous lists of purchase and sales invoices required as supplements to the VAT return; (3) discontinuing the requirement for VAT refund claimants to submit the original copies of all purchase and sales invoices; and (4) streamlining the VAT refund process for taxpayers without gold card status.

Thus far, the compliance simplification initiative has yielded limited results. Significant opportunities for simplifying the VAT have not been realized and the work on streamlining other major taxes has not yet been started. Despite the limited results, compliance simplification remains an important and ongoing reform with progress expected in 2008 .

Improving the legal framework for tax administration. The main purpose of this initiative was to strengthen the DGT's legal framework by revising the rules and procedures governing tax administration. As mentioned in Section II, these rules are contained in two sets of tax laws: the rules that apply to all taxes are stipulated in the general laws on tax administration 
and arrears collection while the rules that apply to a particular tax are provided for in each substantive tax law (income tax, VAT, etc.). Critical shortcomings in this legislation weakened the DGT's capacity to enforce the tax laws and reduced taxpayers' confidence in the fairness of the tax system.

To improve this situation, the authorities carried out an extensive consultation process during 2003 on the tax administration laws with tax and legal experts, officials from international organizations (particularly multilateral donors), and members of the business community (both international and domestic). On the basis of these consultations, an initial package of amendments was formulated in early 2004 which were later revised by the new government that came into office in October 2004. Although these packages contained a number of positive proposals, they also omitted other changes that were critical for effective tax administration, including: restructuring the penalty regime; strengthening the DGT's powers to access taxpayers' and third-party information; and, providing greater fairness in the appeals process.

After protracted deliberations by Parliament over nearly three years, the amendments were finally enacted in 2007 and are expected to enter into effect in 2008. However, given the amendments' limited scope, it remains uncertain whether the new legislation will have much of an impact on enhancing the DGT's capacity to enforce the tax laws or promoting taxpayers' rights. In this situation, the authorities will need to closely monitor the operation of the new legislation and consider further amendments in the event that the legislation does not generate the intended improvements in the legal framework for tax administration.

Increasing audit effectiveness. While the tax audit function is one of a tax agency's most important tools for ensuring that taxpayers comply with the tax laws, it has been one of the weakest links among the DGT's enforcement programs for many years. Although some piecemeal reforms had been introduced in this area under the short-term reform strategy, the DGT's audit capabilities in 2003 continued to face difficulties at detecting the large amounts of underreported taxes and foregone revenue. In this connection, strengthening the DGT's audit function was (and continues to be) a major priority for the medium-term reform strategy.

By 2004, the DGT had identified those aspects of its audit program that were in most urgent need of reform. These included: improving the targeting of audits on those taxpayers who are most likely to be underreporting taxes; introducing a broader range of audit types and methods; training auditors to look beyond a taxpayers' accounting statements to examine source documents and third-party information; increasing the number of audits conducted at taxpayers' premises and greatly reducing the large amount of resources allocated to examining refund claims; implementing more stringent controls and quality assurance programs to deter collusion between taxpayers and auditors; and introducing computerized audit tools. 
Through 2007, insufficient progress had been made in improving the DGT's audit program. Part of the problem seemed to involve the sheer complexity of the reforms, but there also appeared to be a lack of political will to initiate reforms in this sensitive area. A more vigorous reform effort, therefore, will be required to improve this situation. Given the crucial role that audit plays in a modern tax administration and its potential benefits for fiscal adjustment, strengthening the audit program should be considered a top priority for future reform.

Implementing a performance measurement system. The main purpose of this initiative was to develop a comprehensive set of measures for evaluating the DGT's performance. The idea was to broaden the DGT's narrow focus from achieving an annual revenue collection target - which was thought to create perverse incentives for arbitrary administration - to improving its core tax administration processes. This initiative could contribute to the fiscal adjustment program's revenue collection and investment climate effects by creating greater accountability for results and enhanced transparency in administration.

The DGT commenced work on developing new performance measures in late 2004 by reviewing its existing performance measurement practices in comparison to international best practice. The review led to a consensus within the DGT that a new system was needed which should feature performance measures at: (1) at three levels - strategic, operational, and individual and (2) in three broad areas - tax administration programs, taxpayer satisfaction, and employee satisfaction. There was also agreement within the DGT that the new performance measures should be implemented gradually as an integral part of the DGT's modernization program.

At the end of 2007, the DGT had formulated an initial set of performance indicators covering key aspects of its operations. The indicators were expected to be approved by DGT management in early 2008, although considerable effort will still be required before the measures become operational. The slow progress has resulted, in part, from the difficulties in developing reliable measures for some aspects of the DGT's operations in an environment of limited IT systems. Notwithstanding these challenges, performance measurement is a wellaccepted management concept that has been successfully implemented by many tax administrations around the world, even those with limited IT capacities. As such, the implementation of a performance measurement system should be a top priority for the DGT's ongoing reform program.

Reforming human resource management policies. This initiative sought to increase the productivity and integrity of tax officers by providing the DGT with greater flexibilities over its human resource (HR) management policies. The directorate's existing HR regime, which was based on the standard civil service system, was seen as poorly suited for motivating its workforce and establishing accountability for results. For this reason, a more flexible regime 
was viewed as crucial for providing tax officers with the types of incentives needed to transform the DGT into a high-performance revenue collection agency.

Under the DGT's short-term reform program, the DGT had tested a number of important HR reforms at a few pilot tax offices beginning with the large taxpayer office. These reforms included new procedures for appointing staff, a code of conduct for tax officers, and the issuance of a special allowance that had substantially increased salaries. Building on these initial reforms, the DGT reviewed its HR policies in late 2004, which pointed to the need for more comprehensive reforms. In this connection, priority was to be given to developing a new job classification scheme (that would rank jobs on the basis of the complexity of work, overall responsibilities, and specific skills and competencies required), new compensation and promotion policies (that would set salaries at appropriate levels and base raises/promotions on staff members' level of performance), and an improved staff appraisal regime (that would cascade DGT-wide performance measures down to individual tax officers).

By the end of 2007, the DGT was still at a very early stage in reforming its HR regime. The slow progress resulted mainly from the DGT's limited capacity to design the detailed features of the reforms. Consequently, HR reform continues to have considerable potential for improving the DGT's performance, but significant efforts are still needed to realize the potential gains.

Designing an information technology master plan. The key objective of this initiative was to develop an information technology (IT) strategy that was aligned to the directorate's overall medium-term reform plan. In this way, the IT initiative could more effectively support the DGT's taxpayer services and enforcement programs, which were the keys for increasing compliance and revenue. As importantly, advanced information technologies could also help improve the business climate by reducing the need for face-to-face contacts between taxpayers and tax officers, thereby providing taxpayers with greater convenience and limiting the opportunities for rent-seeking behavior by tax officers.

Under the DGT's short-term reform strategy, the directorate had successfully implemented a number of important IT initiatives, the most important of which was to pilot at the large taxpayer office a new computer system that supported core tax administration processes. Over the medium-term, the DGT sought to: (i) gradually roll-out the pilot computer system to all tax offices throughout Indonesia and (ii) improve the pilot system through various enhancements. The latter would include centralizing the processing and storage of taxpayer data (which had previously been carried out by the hundreds of field offices), creating a data warehouse that could cross-match taxpayer and third-party information as well as carry out other compliance functions, and introducing a broad range of new web-based services (such as electronic registration and taxpayers' on-line access to their accounts with the DGT). 
At the end of 2007, the DGT's information technology initiatives had yielded a number of important advances but their full potential for raising tax administration performance had not been realized because the reforms were not underpinned by unified IT strategy. On the positive side, the DGT had, by 2007, deployed the pilot computer system to some 100 field offices, its electronic payment notification system was processing 100 percent of tax payments, a broad range of new electronic services had been introduced, and the DGT was set to deploy its first centralized processing site. However, in the absence of an IT master plan, the DGT found itself operating four separate IT systems which could neither communicate with each other nor produce reliable national data. Going forward, the DGT needs to develop an IT master plan to guide its future investments in technology.

Creating an internal investigation unit. To improve governance among tax officers and other MoF staff, the Indonesian authorities decided in 2003 to create an internal investigation unit at the MoF with the responsibility for investigating allegations of misconduct and corruption within the ministry's directorates. In light of the widespread complaints among taxpayers about malfeasance by tax officers, this initiative sought to restore taxpayers' confidence in the tax administration which, along with other governance-enhancing initiatives, was seen as essential for boosting Indonesia's investment climate.

The internal investigation unit was established as a special section within the MoF's Inspectorate General in November 2004. During 2005, the unit had achieved a satisfactory level of performance as evidenced by: (1) the fact that the unit had been implemented on time and largely in line with good international practice; (2) the number of investigations that had been initiated (51) and completed (33); (3) the significance of cases selected for investigation, with most cases involving serious abuses of authority; and (4) the overall quality of the investigations. However, the unit's overall impact of the internal investigation unit on reducing corruption was seriously hindered by the fact that no tax officers had been referred for prosecution for corruption and bribery offences as a result of the unit's investigations, and that the DGT had applied administrative sanctions against only 23 of the 111 employees where such sanctions had been recommended.

The creation of the internal investigation unit was one of several important actions that the Indonesian authorities had taken to improve integrity in tax administration under the DGT's medium-term strategy. Others included the increase in salary and introduction of a code of conduct for staff at the DGT's pilot offices. Despite these positive steps, citizens' groups and the business community continued to report, at the end of 2005, misconduct by tax officers remained a major problem, particularly outside of the pilot offices. Improving this situation would require, inter alia, ensuring that the investigations of misconduct by tax officers lead to the imposition of appropriate sanctions against corrupt staff, including job termination and imprisonment in cases involving serious offences. The appointment of a new MOF Inspector General in 2006 created an opportunity to move forward in this important area. 


\section{Summary}

Through 2007, the medium-term reforms reached varying states of implementation, with some initiatives fully implemented and achieving good results while others were still at an early stage of development. On the plus side, good progress had been made in rolling-out the initial pilot reforms to additional tax offices, creating model tax offices for administering small and medium-sized taxpayers, and introducing new technologies. On the negative side, slower progress had been made in implementing some of the more far reaching reforms such as amending the tax administration law (which was eventually amended in 2007), simplifying the tax laws, overhauling the audit system, designing new human resource management policies, and establishing a performance measurement system.

Yet despite the mixed results, the DGT's reform program had (and continues to have), in its totality, a demonstrably positive impact on Indonesia's fiscal adjustment strategy, as described in the next section. As importantly, the initial reforms created the foundation for a new modernization program that the DGT's new management adopted in 2006 and is currently ongoing.

\section{IMPACTS OF THE REFORMS}

This section analyzes the impact that the reforms have had on two key objectives in Indonesia's fiscal adjustment strategy: (i) increasing non-oil and gas tax revenue and (ii) improving the investment climate. The available evidence suggests that the reforms had a strong, positive impact on the tax yield and a positive, though difficult to quantify, effect on the investment climate.

\section{A. Impact on Revenue}

Prior to the 1997/98 Asian crisis, (non-oil) tax collection in Indonesia was on a slow but steady downward trend (see earlier Table 1, and Text Figure 1). In the five years prior to the 1997/98 Asian crisis, Indonesia's tax yield averaged 10.5 percent of GDP and then declined and eventually bottomed out at 9.6 percent in 2000. A similar downward trend in collection is also observable as a ratio of non-oil GDP. The decline mostly came from lower DGT collections.

In breaking with pre-crisis (and crisis) trends, the tax yield increased over the period of the tax administration reforms. From 2001 - the year preceding the introduction of the reforms - to 2006 the (non-oil and gas) tax-to-GDP ratio rose from 9.9 to 11.0

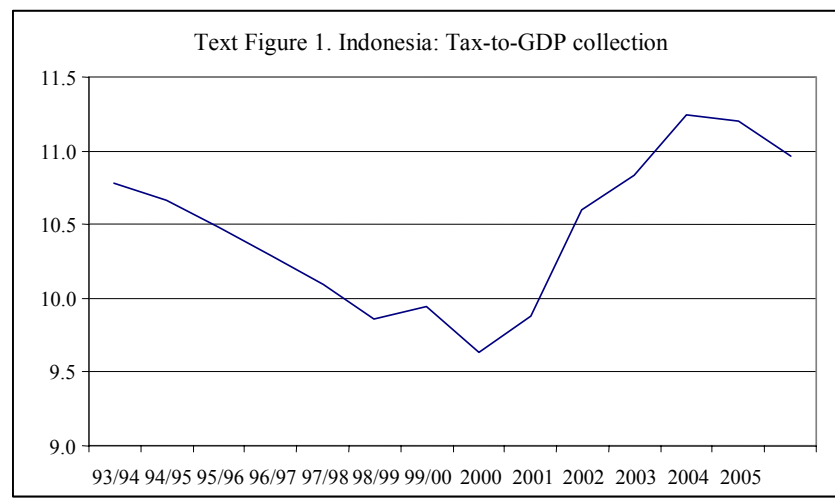


(Table 3). ${ }^{21}$ Over this period, DGT collections rose by 1.2 percentage points of GDP while collections from DG Customs decreased by 0.1 percentage points of GDP. The buoyancy in GDT collection was generated by three taxes: income tax ( 0.6 percentage points of GDP), VAT ( 0.5 percentage points of GDP), and land tax ( 0.3 percentage points); luxury and sales tax collection partly offset this good performance, as it declined by 0.2 percentage points of GDP. In the five reform years beginning in 2001, the average tax yield increased to 11 percent of GDP.

The increased tax buoyancy could have resulted from a mix of: (1) tax policy changes, (2) structural economic changes, and (3) tax administration improvements. Before assessing the likely revenue impact of the latter, we briefly review the revenue impact that the former two factors could have had.

Tax policy effects. Changes in tax policy over the 2002-2006 period were relatively limited and concerned a few taxes only. On the income tax front, no major taxes changes occurred during the reform period - a tax reform package was drafted in 2004 but has not yet been passed by Parliament. Income tax changes, however, did take place on January 1, 2001, with some of revenue impact of these measures falling in 2002; the impact of these measures

seems to be slightly negative for revenue. ${ }^{22}$ The VAT was not subject to any significant tax policy changes during the period. ${ }^{23}$ The luxury sales tax was subject to numerous base and rate changes $^{24}$ (rates now range from 10 to 75 percent, the list of goods subject to the tax is fairly extensive) so that the revenue impact of those tax changes is unclear ex ante. The land and building tax bases and rates were not significantly modified during the reform period.

\footnotetext{
${ }^{21}$ Preliminary estimates of 2007 budgetary execution point to a strong improvement in the non-oil and gas taxto-GDP ratio (see Table 3). Since these are subject to revision, they are not included in the analysis but their inclusion would only reinforce the conclusion reached in the paper.

${ }^{22}$ Regarding the personal income tax (PIT), both the tax brackets and rates were modified, which resulted in a decrease in the effective tax rate for all but the wealthiest tax payers (the top marginal rate was increased from 30 to 35 percent but the threshold for this top marginal rate was increased four-fold). On the corporate income tax (CIT) front, only the tax brackets were changed (the three rates of 10, 15, and 30 percent remain). This resulted in a lower effective tax rate for corporations.

${ }^{23}$ In 2003, VAT exemptions were granted for goods traded in bonded zones as long as these goods, including those imported, are used in the production of exported goods (Government Regulation 60). Other recent changes, but that pre-date the administration reforms, took place in 2000 are concerned the VAT base (Law 18 and Government Regulation 144 detailed the exempted sectors), and, to a lower extent in 2001 (Government Regulation 21 added some "strategic" products to the 2000 list).

${ }^{24}$ The list of goods subject to the luxury sales tax is extensive; it includes alcoholic beverages (which are also subject to excises), motor vehicles, soft drinks, household appliances, cosmetics, electronics, and carpets. Rates range between 10 and 75 percent. It is a final tax, which is not creditable for VAT purposes.
} 
Structural economic effects Changes in Indonesia's economic structure were more significant since the economy was recovering from a major economic and financial crisis. This is likely to have affected tax collection through several channels. For CIT, the Asian crisis is likely to have materially impacted revenue collection up to 2002 due to the slow winding down of loss carry-forward provisions and of tax relief for the restructuring of businesses completed in the tax years 2000 to 2002. For PIT, the labor market strengthened significantly from its trough during the Asian crisis which impacted both the base (less unemployed individuals) and the salary of each worker. Hence, an improved income tax buoyancy is expected. Similarly, VAT buoyancy should also be up due to a recovery in domestic consumption. The land and building taxes rely heavily on collections from mining resources and other natural resources rather than developed real estate. Due to booming commodity prices over the reform period, an improved tax elasticity is expected. 
Table 3. Indonesia: Summary of Central Government Operations, 2000-2007

\begin{tabular}{|c|c|c|c|c|c|c|c|c|}
\hline & $20001 /$ & 2001 & 2002 & 2003 & 2004 & 2005 & 2006 & 2007 \\
\hline & Act. & Act. & Act. & Act. & Act. & Act. & Act. & Est. \\
\hline & \multicolumn{8}{|c|}{ (Rp trillions) } \\
\hline Total Revenue and grants & 228.1 & 301.2 & 300.0 & 336.4 & 407.9 & 495.4 & 634.0 & 705.9 \\
\hline Oil and gas revenue & 85.1 & 104.1 & 77.8 & 80.4 & 108.2 & 138.7 & 201.3 & 168.5 \\
\hline Non-oil and gas revenue & 143.0 & 196.6 & 221.9 & 255.6 & 299.4 & 355.4 & 430.9 & 535.7 \\
\hline Tax revenue & 127.8 & 162.6 & 193.1 & 218.1 & 258.0 & 311.8 & 365.9 & 447.4 \\
\hline Directorate General of Taxes & 109.5 & 135.6 & 159.2 & 180.6 & 216.1 & 263.3 & 314.9 & 381.9 \\
\hline Income tax & 58.3 & 71.5 & 84.5 & 93.8 & 112.0 & 140.3 & 165.6 & 194.6 \\
\hline VAT \& luxury sales tax & 44.4 & 56.0 & 65.2 & 74.2 & 87.6 & 101.3 & 123.0 & 155.0 \\
\hline VAT & 39.0 & 50.2 & 59.4 & 71.0 & 81.0 & 93.3 & 117.8 & $\ldots$ \\
\hline Domestic & 21.9 & 30.0 & 37.3 & 47.1 & 46.3 & 47.5 & 74.7 & $\ldots$ \\
\hline Imports & 17.1 & 20.2 & 22.1 & 23.9 & 34.7 & 45.8 & 43.1 & $\ldots$ \\
\hline Land tax & 5.7 & 6.7 & 8.0 & 10.9 & 14.7 & 19.6 & 23.9 & 29.5 \\
\hline Other taxes & 1.1 & 1.4 & 1.5 & 1.7 & 1.8 & 2.1 & 2.3 & 2.7 \\
\hline Directorate General of Customs & 18.3 & 27.0 & 33.9 & 37.5 & 41.9 & 48.5 & 51.0 & 65.5 \\
\hline Non-tax revenue & 15.2 & 34.0 & 28.8 & 37.5 & 41.4 & 43.6 & 65.0 & 88.3 \\
\hline \multirow[t]{2}{*}{ Grants } & 0.0 & 0.5 & 0.3 & 0.4 & 0.3 & 1.3 & 1.9 & 1.7 \\
\hline & \multicolumn{8}{|c|}{ (percent of GDP) } \\
\hline Total Revenue and grants & 19.3 & 18.3 & 16.5 & 16.7 & 17.8 & 17.9 & 19.0 & 17.8 \\
\hline Oil and gas revenue & 8.2 & 6.3 & 4.3 & 4.0 & 4.7 & 5.0 & 6.0 & 4.3 \\
\hline Non-oil and gas revenue & 11.1 & 11.9 & 12.2 & 12.7 & 13.0 & 12.8 & 12.9 & 13.5 \\
\hline Tax revenue & 9.6 & 9.9 & 10.6 & 10.8 & 11.2 & 11.2 & 11.0 & 11.3 \\
\hline Directorate General of Taxes & 7.9 & 8.2 & 8.7 & 9.0 & 9.4 & 9.5 & 9.4 & 9.6 \\
\hline Income tax & 4.2 & 4.3 & 4.6 & 4.7 & 4.9 & 5.1 & 5.0 & 4.9 \\
\hline VAT \& luxury sales tax & 3.2 & 3.4 & 3.6 & 3.7 & 3.8 & 3.7 & 3.7 & 3.9 \\
\hline VAT & 2.8 & 3.0 & 3.3 & 3.5 & 3.5 & 3.4 & 3.5 & $\ldots$ \\
\hline Domestic & 1.6 & 1.8 & 2.0 & 2.3 & 2.0 & 1.7 & 2.2 & $\ldots$ \\
\hline Imports & 1.2 & 1.2 & 1.2 & 1.2 & 1.5 & 1.7 & 1.3 & $\ldots$ \\
\hline Land tax & 0.4 & 0.4 & 0.4 & 0.5 & 0.6 & 0.7 & 0.7 & 0.7 \\
\hline Other taxes & 0.1 & 0.1 & 0.1 & 0.1 & 0.1 & 0.1 & 0.1 & 0.1 \\
\hline Directorate General of Customs & 1.8 & 1.6 & 1.9 & 1.9 & 1.8 & 1.7 & 1.5 & 1.7 \\
\hline Non-tax revenue & 1.5 & 2.1 & 1.6 & 1.9 & 1.8 & 1.6 & 1.9 & 2.2 \\
\hline \multirow[t]{2}{*}{ Grants } & 0.0 & 0.0 & 0.0 & 0.0 & 0.0 & 0.0 & 0.1 & 0.0 \\
\hline & \multicolumn{8}{|c|}{ (percent of non-oil GDP) } \\
\hline Total Revenue and grants & 22.0 & 20.9 & 18.8 & 19.1 & 20.3 & 20.4 & 21.7 & 20.3 \\
\hline Oil and gas revenue & 9.3 & 7.2 & 4.9 & 4.6 & 5.4 & 5.7 & 6.9 & 4.9 \\
\hline Non-oil and gas revenue & 12.7 & 13.6 & 13.9 & 14.5 & 14.9 & 14.6 & 14.7 & 15.4 \\
\hline Tax revenue & 11.0 & 11.3 & 12.1 & 12.4 & 12.8 & 12.8 & 12.5 & 12.9 \\
\hline Directorate General of Taxes & 9.0 & 9.4 & 10.0 & 10.2 & 10.7 & 10.8 & 10.8 & 11.0 \\
\hline Income tax & 4.8 & 5.0 & 5.3 & 5.3 & 5.6 & 5.8 & 5.7 & 5.6 \\
\hline VAT \& luxury sales tax & 3.6 & 3.9 & 4.1 & 4.2 & 4.4 & 4.2 & 4.2 & 4.5 \\
\hline Land tax & 0.5 & 0.5 & 0.5 & 0.6 & 0.7 & 0.8 & 0.8 & 0.8 \\
\hline Other taxes & 0.1 & 0.1 & 0.1 & 0.1 & 0.1 & 0.1 & 0.1 & 0.1 \\
\hline Directorate General of Customs & 2.0 & 1.9 & 2.1 & 2.1 & 2.1 & 2.0 & 1.7 & 1.9 \\
\hline Non-tax revenue & 1.7 & 2.4 & 1.8 & 2.1 & 2.1 & 1.8 & 2.2 & 2.5 \\
\hline Grants & 0.0 & 0.0 & 0.0 & 0.0 & 0.0 & 0.1 & 0.1 & 0.0 \\
\hline & \multicolumn{8}{|c|}{ (percent of total revenue and grants) } \\
\hline Total Revenue and grants & 100.0 & 100.0 & 100.0 & 100.0 & 100.0 & 100.0 & 100.0 & 100.0 \\
\hline Oil and gas revenue & 37.3 & 34.6 & 25.9 & 23.9 & 26.5 & 28.0 & 31.7 & 23.9 \\
\hline Non-oil and gas revenue & 62.7 & 65.3 & 74.0 & 76.0 & 73.4 & 71.7 & 68.0 & 75.9 \\
\hline Tax revenue & 56.0 & 54.0 & 64.4 & 64.8 & 63.3 & 62.9 & 57.7 & 63.4 \\
\hline Directorate General of Taxes & 48.0 & 45.0 & 53.1 & 53.7 & 53.0 & 53.1 & 49.7 & 54.1 \\
\hline Income tax & 25.6 & 23.7 & 28.2 & 27.9 & 27.5 & 28.3 & 26.1 & 27.6 \\
\hline VAT \& luxury sales tax & 19.5 & 18.6 & 21.7 & 22.1 & 21.5 & 20.4 & 19.4 & 22.0 \\
\hline Land tax & 2.5 & 2.2 & 2.7 & 3.2 & 3.6 & 4.0 & 3.8 & 4.2 \\
\hline Other taxes & 0.5 & 0.5 & 0.5 & 0.5 & 0.4 & 0.4 & 0.4 & 0.4 \\
\hline Directorate General of Customs & 8.0 & 9.0 & 11.3 & 11.1 & 10.3 & 9.8 & 8.0 & 9.3 \\
\hline Non-tax revenue & 6.7 & 11.3 & 9.6 & 11.1 & 10.1 & 8.8 & 10.3 & 12.5 \\
\hline Grants & 0.0 & 0.2 & 0.1 & 0.1 & 0.1 & 0.3 & 0.3 & 0.2 \\
\hline \multicolumn{9}{|l|}{ Memorandum items } \\
\hline Nominal non-oil GDP (Rp. trillions) & 1,218 & 1,443 & 1,597 & 1,765 & 2,013 & 2,432 & 2,928 & 3,469 \\
\hline Nominal GDP (Rp. trillions) & 1,390 & 1,646 & 1,822 & 2,014 & 2,296 & 2,774 & 3,339 & 3,957 \\
\hline
\end{tabular}


Tax administration effects. In light of the above tax policy and structural changes, isolating the revenue impact of tax administration reforms involves a number of methodological and data challenges. The approach adopted here is to focus on analyzing the factors that accounted for the increase in VAT collections, where the availability of data makes the analysis more tractable. In doing so, the analysis derives the tax administration effects on VAT collections as the residual between actual and projected VAT revenue, with the latter controlling for changes in economic structure (as previously mentioned, there were no significant VAT policy changes since 2001 that need to be controlled). A simple macrobased estimation of the VAT revenue collection (using a GDP decomposition so as to estimate aggregate final consumption, which is the taxable base for VAT) is shown in Table 4 (see Appendix II for details of the methodology). ${ }^{25}$

The analysis of VAT collection reveals that more than half of the VAT revenue buoyancy is due to tax administration improvement (Table 4). Based on the changes in the economic structure from 2001 to 2006 , VAT revenue collection was projected to increase by 0.21 percentage points of GDP. Actual collection, however, increased by 0.48 percentage points of GDP. Since there were no tax policy changes during that period that could explain the remaining increase in VAT collections, it can be concluded that the DGT's comprehensive tax administration reforms described in the previous sections and reflected in an increasing implicit compliance rate in Table 4 account for the residual 0.27 percentage points of GDP in over performance (more than half of the increased tax yield). Consistent with the above conclusion, various productivity indicators (VAT efficiency; VAT C-efficiency out of total and private consumptions - see details in Appendix II) also report an improvement in the efficiency of the value added tax. Consistent with the revenue overperformance linked to administrative reforms, VAT compliance increased from 52.9 percent in 2001 to 57.3 percent in 2006 - an increase of 8.3 percent over the pre-reform compliance level (Table 4).

\footnotetext{
${ }^{25}$ A summary of the methodology is the following. The projections are calibrated for the year 2000 based on the tax gap obtained by Marks (2005), with the economy's exemption rate backed up from the compliance rate and actual revenue collection for that year. Holding the nonexemption rate constant for the remaining years (as no significant tax policy changes occurred), a compliance rate is derived (by matching projected and actual VAT collection) for 2001, the year prior to the tax administration reforms. The projected revenue for 2002 to 2006 take into account changes in the GDP composition (e.g., import growth exceeding that of export, which is revenue positive for VAT collection), while holding tax compliance at the 2001 (pre reform) level of 52.9 percent.
} 
Table 4. Indonesia: VAT Revenue Projections Based on GDP Decomposition, 2000-2006

\begin{tabular}{|c|c|c|c|c|c|c|c|}
\hline & $\begin{array}{r}2000 \\
\text { Act. }\end{array}$ & $\begin{array}{r}2001 \\
\text { Act. }\end{array}$ & $\begin{array}{r}2002 \\
\text { Act. }\end{array}$ & $\begin{array}{r}2003 \\
\text { Act. }\end{array}$ & $\begin{array}{r}2004 \\
\text { Act. }\end{array}$ & $\begin{array}{r}2005 \\
\text { Act. }\end{array}$ & $\begin{array}{r}2006 \\
\text { Prel. Act. }\end{array}$ \\
\hline & \multicolumn{7}{|c|}{ (In trillion Rp. Unless otherwise specified) } \\
\hline Nominal GDP & 1,390 & 1,646 & 1,822 & 2,014 & 2,296 & 2,785 & 3,338 \\
\hline Imports (cif) & 366 & 385 & 357 & 362 & 490 & 731 & 734 \\
\hline Export (fob) & -549 & -588 & -551 & -550 & -632 & -844 & -949 \\
\hline Final base consumption & 1,207 & 1,443 & 1,628 & 1,826 & 2,154 & 2,671 & 3,123 \\
\hline Exemption rate (percent) $1 /$ & $34.2 \%$ & $34.2 \%$ & $34.2 \%$ & $34.2 \%$ & $34.2 \%$ & $34.2 \%$ & $34.2 \%$ \\
\hline Consumption subject to VAT & 794 & 950 & 1,071 & 1,202 & 1,417 & 1,758 & 2,055 \\
\hline Statutory tax rate (percent) & $10.0 \%$ & $10.0 \%$ & $10.0 \%$ & $10.0 \%$ & $10.0 \%$ & $10.0 \%$ & $10.0 \%$ \\
\hline Potential VAT collection & 79 & 95 & 107 & 120 & 142 & 176 & 206 \\
\hline Compliance rate (percent of potential VAT) & $49.1 \%$ & $52.9 \%$ & $52.9 \%$ & $52.9 \%$ & $52.9 \%$ & $52.9 \%$ & $52.9 \%$ \\
\hline Estimated VAT revenue (assuming unchanged compliance) & 39.0 & 50.2 & 56.7 & 63.6 & 75.0 & 93.0 & 108.7 \\
\hline Actual VAT revenue & 39.0 & 50.2 & 59.4 & 71.0 & 81.0 & 93.3 & 117.8 \\
\hline \multirow[t]{2}{*}{ Implicit compliance rate (percent of potential VAT) $2 /$} & $49.1 \%$ & $52.9 \%$ & $55.4 \%$ & $59.1 \%$ & $57.2 \%$ & $53.1 \%$ & $57.3 \%$ \\
\hline & \multicolumn{7}{|c|}{ (in percent of GDP) } \\
\hline Estimated VAT revenue (assuming unchanged compliance) & 2.81 & 3.05 & 3.11 & 3.16 & 3.27 & 3.34 & 3.26 \\
\hline Actual VAT revenue & 2.80 & 3.05 & 3.26 & 3.53 & 3.53 & 3.35 & 3.53 \\
\hline Domestic & 1.58 & 1.82 & 2.05 & 2.34 & 2.02 & 1.71 & 2.24 \\
\hline Imports & 1.22 & 1.23 & 1.21 & 1.19 & 1.51 & 1.65 & 1.29 \\
\hline \multicolumn{8}{|l|}{ Memo items } \\
\hline VAT efficiency ratio & $28.0 \%$ & $30.5 \%$ & $32.6 \%$ & $35.3 \%$ & $35.3 \%$ & $33.5 \%$ & $35.3 \%$ \\
\hline VAT C-efficiency ratio (total consumption) & $32.3 \%$ & $34.8 \%$ & $36.5 \%$ & $38.9 \%$ & $37.6 \%$ & $34.9 \%$ & $37.7 \%$ \\
\hline VAT C-efficiency ratio (private consumption) & $39.0 \%$ & $46.1 \%$ & $45.6 \%$ & $48.8 \%$ & $47.2 \%$ & $43.4 \%$ & $48.0 \%$ \\
\hline
\end{tabular}

Source: Authors calculations

1/ Derived as a residual from Marks (2005).

2/ Calculated as the residual from the potential VAT base and actual VAT collected.

Conducting a similar analysis for CIT and PIT collections is particularly difficult in Indonesia since only aggregate income tax data are available. This is because the data are presented by nature of collection rather than corporate or personal income taxpayer. Without this breakdown, modeling the (different) corporate and individual income tax bases and their evolution over the reform period would be futile since one cannot compare these projections with actual CIT and PIT collections. Despite this, and the expected positive revenue impact that the termination of tax relief after 2002 had on revenue collection, it is worth noting that the income tax yield continued to increase from 2003 to 2006 (by 0.3 percentage points of GDP or 0.4 percentage points of non-oil GDP)—Table 4 . Given the comprehensive nature of the DGT's reform program, it is not unreasonable to conclude that tax administration improvements likely had a similar significant impact on the increase in income tax collections as has been shown for VAT collections. 
Data that also point to a significant revenue impact of the tax administration reforms can be seen from the compliance control indicators established by the DGT during 2002-2005. ${ }^{26}$ These indicators include tax arrears collection, the proportion of taxpayers that are late filers, and the proportion of late payers. As described in Section III.A, improved DGT efficiency could be expected to lead to the following pattern in the data. First, in the initial phase of reforms - when the tax administration improves its enforcement capacity - the share of revenue collection stemming from enforced collection to total DGT collection should increase. Second, as taxpayers increase their voluntary compliance rates in response to the tax agency's stepped up enforcement efforts, the share of enforced collection to total collection should gradually decline. DGT data (shown in Table 5) reveal that:

- The share of both late filers and late payers has decreased over time in the pilot DGT offices that went through the reform program.

- The trend in arrears collection data is consistent with improved tax compliance in the economy (the share of enforced to total DGT collection first rises then decline over time).

A more compelling analysis of the tax compliance impact of the DGT reforms arises from the comparison in voluntary tax collections at the pilot tax offices relative to nonpilot tax offices. This approach treats the nonpilot tax offices as a "control group." Interestingly, for our control group analysis, the DGT administrative reforms were introduced in a staggered manner beginning with four pilot tax offices. Specifically, the reforms were first introduced in July 2002 with the Large Taxpayer Office (LTO), and then extended 2004 to three additional tax offices: (i) the Special Region Office (SRO) which also administers large taxpayers; (ii) the Medium Taxpayer Office (MTO); and (iii) the Small Taxpayer Office (STO). While some of the pilot reforms were subsequently introduced to all tax offices nationwide, the most far-reaching reforms have been implemented only at these four pilot offices. ${ }^{27}$ With the LTO and the SRO together accounting for about half of DGT's total collection, tax-administration-induced increases in compliance, if successful, should have a noticeable revenue impact.

The data reveal a striking and consistent increase in voluntary collections at each of the pilot offices, while nonpilot offices experienced no such increase (Table 5). For instance, the LTO in 2002 and 2003 had the same number of large taxpayers (200) but voluntary tax collection

\footnotetext{
${ }^{26}$ DGT started to measure enforced collections only in 2002, the first year of the tax administration reform program. Without a base for comparison in 2001, it is not possible to measure the increase in enforced collections from 2001 to 2002. Given the weakness in the DGT's enforcement programs prior to 2002 (as revealed by the steadily declining DGT tax-to-GDP collection ratio since FY1993/94), the pattern of improved compliance shown from 2002 to 2005 is likely to understate the true revenue impact of the tax administration improvements (i.e., compared to 2001).

${ }^{27}$ These include the reorganization of staff into units based on tax administration function, the vetting of managers and staff, increased salaries, application of a code of conduct, and better taxpayer services.
} 
jumped from 1.5 to 1.8 percent of GDP between these two years, while the rest of DGT's collection remains flat at 7.2 percent of GDP. The same pattern emerged between 2004 and 2005: voluntary collection at both the LTO and the MTO grew faster (again, holding the number of taxpayers constant) than the rest of DGT's tax collection. The Special Region also witnessed a much faster increase in revenue collection than observed in the rest of the DGT. However, since the number of taxpayers in this region also increased, a proper benchmark is to compare revenue growth per taxpayer at the SRO with overall DGT revenue growth. The result is also quite stark: SRO revenue per taxpayer rose by 29 percent between 2004 and 2005, while nonmodernized DGT offices saw revenue increases of 10 percent (and overall DGT growth rose by 22 percent). ${ }^{28}$

Significant improvements in compliance indicators at the DGT pilot offices offer further evidence that the better performance of the pilot offices is linked to improved tax administration. Specifically, the strong revenue performance at the pilot offices was accompanied by a dramatic increase in two key compliance indicators: the timely filing of tax returns and the timely payment of taxes (Table 5). One could indeed argue that, although unlikely, a recovery in corporate profits, wage bill growth, and value added of firms could have fortuitously coincided with the modernization of DGT's offices. The fact that the DGT modernization effort (i) has been staggered over several years; and (ii) concerned a representative sample of small, medium, and large taxpayers make such a series of coincidences a low probability event.

Taken together, these data provide evidence that the DGT's reforms led to an improvement in taxpayers' compliance rates at the pilot offices, which was in turn associated with significantly higher increases in voluntary collections compared to the national trend.

\footnotetext{
${ }^{28}$ The LTO and SR represented about half of the DGT's voluntary collections in 2004 but accounted for 75 percent of the Rp. 48 trillion increase in these collections from 2004-05.
} 
Table 5. Indonesia: Selected DGT Performance Indicators, 2002-2005

\begin{tabular}{|c|c|c|c|c|c|}
\hline & 2001 & 2002 & 2003 & 2004 & 2005 \\
\hline & \multicolumn{5}{|c|}{ (In percent of GDP unless otherwise specified) } \\
\hline Total DGT collections & 8.23 & 8.74 & 8.97 & 9.41 & 9.45 \\
\hline Enforced collection & $\ldots$ & 0.47 & 0.54 & 0.94 & 0.73 \\
\hline Voluntary collection & $\ldots$ & 8.27 & 8.43 & 8.48 & 8.73 \\
\hline Enforced collection (percent of DGT collection) & & 5.4 & 6.0 & 9.9 & 7.7 \\
\hline Total DGT collections & 8.23 & 8.74 & 8.97 & 9.41 & 9.45 \\
\hline Non-modernized offices & 8.23 & 7.20 & 7.17 & 4.56 & 4.12 \\
\hline $\begin{array}{l}\text { Modernized offices 1/ } \\
\text { of which: }\end{array}$ & - & 1.54 & 1.80 & 4.85 & 5.33 \\
\hline \multicolumn{6}{|l|}{ Large Taxpayer Office } \\
\hline Total taxes collected & $\ldots$ & 1.54 & 1.80 & 2.17 & 2.34 \\
\hline Enforced & $\ldots$ & 0.02 & 0.04 & 0.05 & 0.10 \\
\hline Voluntary & $\ldots$ & 1.52 & 1.76 & 2.12 & 2.24 \\
\hline Number taxpayers & $\ldots$ & 200 & 200 & 297 & 296 \\
\hline Late filers (percent) & $\ldots$ & 9.0 & 34.0 & 20.9 & 16.6 \\
\hline Late payers (percent) & $\ldots$ & 13.5 & 32.5 & 25.3 & 17.6 \\
\hline \multicolumn{6}{|l|}{ Special Region } \\
\hline Total taxes collected & $\ldots$ & $\ldots$ & $\ldots$ & 2.51 & 2.80 \\
\hline Enforced & $\ldots$ & $\ldots$ & $\ldots$ & 0.57 & 0.37 \\
\hline Voluntary & $\ldots$ & $\ldots$ & $\ldots$ & 1.94 & 2.43 \\
\hline Number taxpayers & $\ldots$ & $\ldots$ & $\ldots$ & 27,575 & 32,445 \\
\hline Late filers (percent) & $\ldots$ & $\ldots$ & $\ldots$ & 15.0 & 6.2 \\
\hline Late payers (percent) & $\ldots$ & $\ldots$ & $\ldots$ & 4.6 & 3.6 \\
\hline
\end{tabular}

Source: GDT and authors calculations.

1/ Data for the Medium Tax Offices and the Small Tax Offices are not reported but available from the authors.

\section{Summary}

The DGT's tax administration reforms are estimated to have accounted for over half of the 1.2 percentage points of GDP increase in tax collection over the reform period. The evolution of the above compliance indicators confirms the results stemming from the analysis of VAT collection, namely that DGT's reforms improved overall tax compliance which led to a significant boost in tax buoyancy. Assuming that the impact of DGT reforms on revenue collection is the same for income tax and the VAT, then tax administration reform would account for 0.35 percentage points of GDP out of the 0.6 percentage points of GDP increase in income tax from 2001 to 2006 . Combined with the revenue improvement in the VAT, the revenue generated by the DGT reforms would be over 0.6 percentage points of GDP. 
From this perspective, the contribution of the tax administration reforms to the overall fiscal adjustment effort during 2001-2006 was significant. The overall fiscal balance improved by 2.2 percentage points of GDP over the period, of which 0.7 percentage points stemmed from revenue and grants (Table 6). Tax revenue was the only revenue category that did not decline over the period and tax administration reforms are estimated to have increased tax revenue by 0.6 percentage points. Without this tax administration-induced increase in tax revenue, total revenue and grants would have been flat over the period and only about two-thirds of the improvement in the overall fiscal balance would have been realized. The improvement in the government's balance was critical in helping Indonesia to attain a more sustainable fiscal position, as gross government debt was sharply reduced from 77.0 percent of GDP in 2001 to 39 percent of GDP in 2006.

Table 6. Indonesia: Sources of the Fiscal Consolidation, 2001-2006

\begin{tabular}{|c|c|c|c|c|c|c|}
\hline & $\begin{array}{r}2001 \\
\text { Act. }\end{array}$ & $\begin{array}{r}2002 \\
\text { Act. }\end{array}$ & $\begin{array}{r}2003 \\
\text { Act. }\end{array}$ & $\begin{array}{r}2004 \\
\text { Act. }\end{array}$ & $\begin{array}{r}2005 \\
\text { Act. }\end{array}$ & $\begin{array}{r}2006 \\
\text { Prel. Act. } \\
\end{array}$ \\
\hline & \multicolumn{6}{|c|}{ (In percent of GDP) } \\
\hline Revenues and grants & 18.3 & 16.5 & 16.7 & 17.8 & 17.8 & 19.0 \\
\hline Oil and gas revenues & 6.3 & 4.3 & 4.0 & 4.7 & 5.0 & 6.0 \\
\hline Non-oil and gas revenues & 11.9 & 12.2 & 12.8 & 13.0 & 12.8 & 12.9 \\
\hline Tax revenues & 9.9 & 10.6 & 10.8 & 11.2 & 11.2 & 11.0 \\
\hline Nontax revenues & 2.1 & 1.6 & 2.0 & 1.8 & 1.6 & 1.9 \\
\hline Grants & 0.0 & 0.0 & 0.0 & 0.0 & 0.0 & 0.1 \\
\hline Expenditure and net lending & 21.5 & 18.0 & 18.7 & 19.1 & 18.1 & 20.0 \\
\hline Overall balance 3 / & -3.2 & -1.6 & -2.0 & -1.4 & -0.3 & -1.0 \\
\hline \multicolumn{7}{|l|}{ Memorandum items: } \\
\hline Public debt & 77.0 & 65.4 & 58.3 & 55.2 & 45.6 & 38.8 \\
\hline
\end{tabular}

Preliminary estimates for 2007 point to a continued positive impact of tax administrative reforms on tax revenue collection. The (non oil and gas) tax yield increased to an all time high of 11.3 percent of GDP, which was mainly due to a record high collection from the DGT (9.6 percent of GDP). This strong performance occurred in an environment with no tax policy changes but with the implementation of a new round of tax administration reforms (that designed in 2006 and took hold in 2007). 


\section{B. Impact on the Investment Climate}

Indonesia's investment rate dropped sharply during the Asian crisis and has only partly recovered since. Prior to the Asian crisis, Indonesia's gross fixed investment as a share of GDP averaged 27 percent from 1994-97 (Text Table 1). During this time, Indonesia was one of the region's favored destinations for foreign direct investment (FDI), as FDI inflows reached \$US 6.2 billion in 1996. As Indonesia was hit by the economic and financial crisis, the investment share dropped sharply in 1998 to 22.3 percent before eventually bottoming out at 18.1 percent in 1999. Investment has since rebounded but only to a level of around 22 percent of GDP in 2006. Similarly, FDI inflows turned negative in 1998 and then dropped sharply in each of the next three years only to recover from 2004 onwards.
Text Table 1. Indonesia: Trends in Investment Performance, 1994-2006

\begin{tabular}{|c|c|c|}
\hline Year & $\begin{array}{c}\text { Gross Fixed } \\
\text { Investment }\end{array}$ & $\begin{array}{c}\text { Net FDI } \\
\text { Inflows }\end{array}$ \\
\hline & (Percent of GDP) & (US\$ billions) \\
\hline 1994 & 24.9 & 2.1 \\
\hline 1995 & 26.2 & 4.3 \\
\hline 1996 & 27.9 & 6.2 \\
\hline 1997 & 28.9 & 4.7 \\
\hline 1998 & 22.3 & -0.2 \\
\hline 1999 & 18.1 & -1.9 \\
\hline 2000 & 19.9 & -4.6 \\
\hline 2001 & 20.4 & -3.0 \\
\hline 2002 & 20.4 & 0.1 \\
\hline 2003 & 19.6 & -0.6 \\
\hline 2004 & 21.4 & 1.9 \\
\hline 2005 & 22.5 & 8.3 \\
\hline 2006 & 21.9 & 5.6 \\
\hline
\end{tabular}

Indonesia's investment climate and competitiveness is poor compared to emerging regional economies although some improvement has occurred recently. In terms of competitiveness, Indonesia ranks in the lowest quartiles when comparing with other emerging regional economies (and globally), a situation that has been relatively stable from 2001 to 2007Table 7. However, the investment climate, as assessed by the International Country Risk Guide's overall country ranking, showed a marked improvement over the past few years; whereas Indonesia ranked last among regional countries in 2000, it out-ranked both Thailand, the Philippines and was close to both India and Vietnam by 2007.

Table 7. Indonesia: Investment Climate Indicators, 2000-2007

\begin{tabular}{|c|c|c|c|c|c|c|c|c|}
\hline \multirow[t]{2}{*}{ Countries } & \multicolumn{4}{|c|}{$\begin{array}{c}\text { International Country Risk Guide } \\
\text { Overall Ranking }\end{array}$} & \multicolumn{4}{|c|}{$\begin{array}{c}\text { IMD World Competitiveness Yearbook } \\
\text { Overall Ranking }\end{array}$} \\
\hline & 2000 & 2002 & 2005 & 2007 & 2001 & 2002 & 2005 & 2007 \\
\hline Indonesia & 118 & 122 & 109 & 77 & 45 & 47 & 60 & 54 \\
\hline China & 47 & 49 & 52 & 30 & 35 & 23 & 21 & 15 \\
\hline India & 77 & 85 & 65 & 73 & 43 & 34 & 39 & 27 \\
\hline Malaysia & 36 & 35 & 32 & 23 & 26 & 26 & 31 & 23 \\
\hline Philippines & 59 & 61 & 81 & 82 & 37 & 19 & 26 & 45 \\
\hline Singapore & 3 & 4 & 6 & 6 & 1 & 2 & 2 & 2 \\
\hline South Korea & 23 & 26 & 23 & 29 & 31 & 32 & 47 & 29 \\
\hline Thailand & 45 & 52 & 62 & 89 & 39 & 20 & 14 & 33 \\
\hline Vietnam & 74 & 77 & 77 & 68 & ... & ... & ... & ... \\
\hline Number countries & 140 & 140 & 140 & 140 & 49 & 49 & 60 & 55 \\
\hline
\end{tabular}

Source: ICGR, IMD. 
Business surveys reveal that tax administration was perceived as, and remains, one of the top impediments to investment (Figure 2). A joint study by the Asian Development Bank and World Bank in 2003 revealed that firms in Indonesia perceived the most critical investment obstacles to be macroeconomic instability and economic and regulatory policy uncertainty, followed by corruption, taxation, financing, labor issues, and infrastructure. 47 percent of surveyed firms viewed tax administration as a moderate to very severe business obstacle (ADB-WB, 2005). Improving tax administration was therefore expected to favorably impact the investment climate in Indonesia. The 2003 ADB-WB study was updated by these institutions in 2005 and in 2007. The updates reveal that, at the national level, tax administration is still seen as a key obstacle to investment, with no perceived improvement since 2003 (however, as detailed below, several factors can reconcile the overall negative perception of the tax administration for the investment climate with the numerous taxpayers' surveys that reveal high satisfaction with the DGT pilot offices).

Figure 2. Indonesia: Obstacles to Investment, 2003, 2005, and 2007

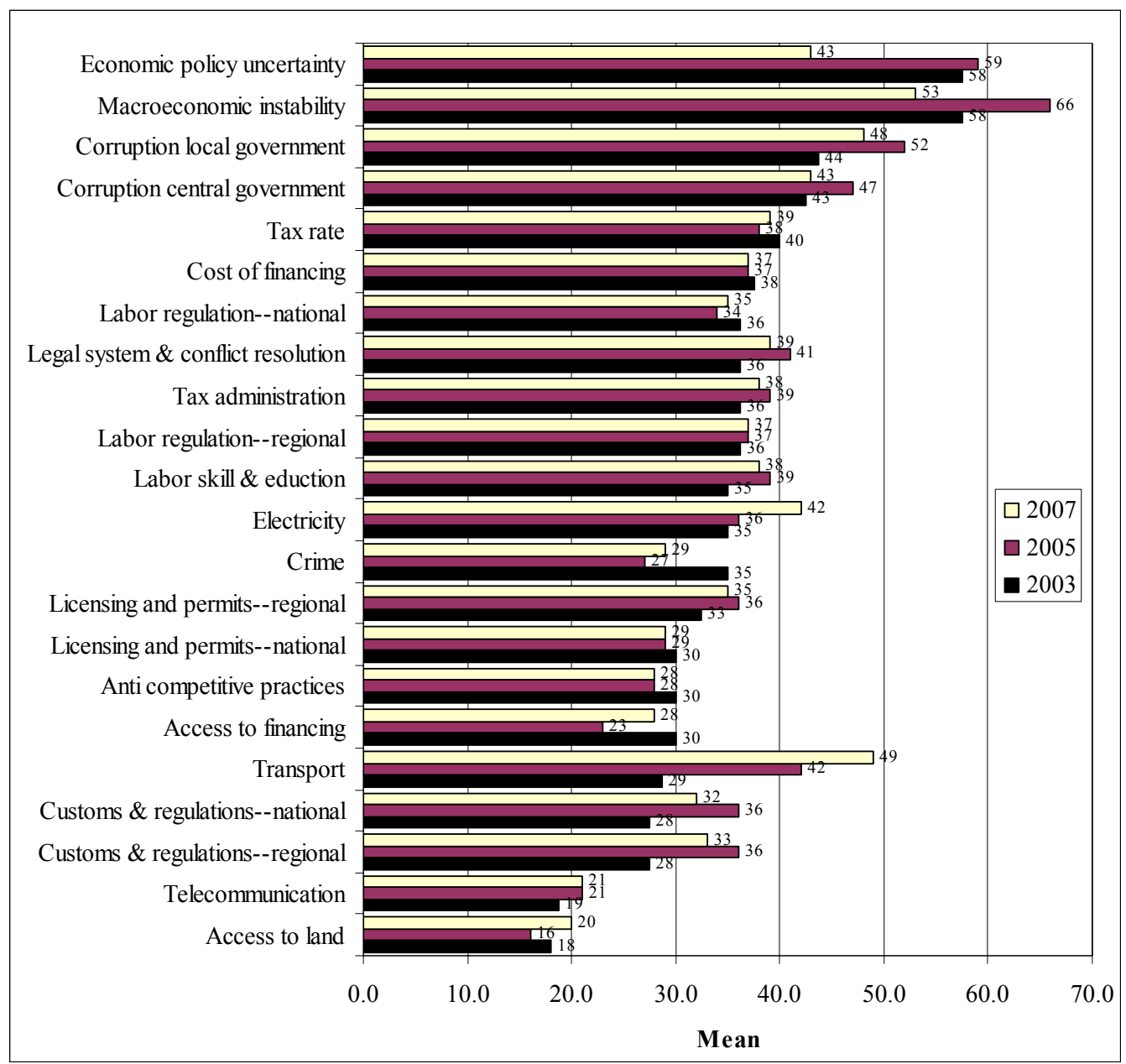

Source: ADB and WB, Investment Climate and Productivity Study (2003, 2005, and 2007). 
Despite the overall negative perception of the tax administration, several surveys of taxpayers reveal that satisfaction with the DGT pilot offices is very high. One such study was undertaken in June 2005 by AC Nielsen. That survey entailed a comprehensive assessment of taxpayer satisfaction with the DGT's Large Taxpayers Office. ${ }^{29}$ Based on Nielson's eQ method for measuring customer satisfaction, the LTO scored an overall performance rating of 81 percent, indicating an exceptionally high level of taxpayer satisfaction. Among the survey's respondents, about 85 percent reported that the LTO reforms dramatically simplified their tax obligations and nearly 80 percent reported positive changes in tax officer behavior.

Detailed questions from the Nielsen survey revealed the comparative strengths of the LTO lies in its professional integrity as well as its taxpayer services, simplicity and efficiency, and information resources. These findings are noteworthy since they provide evidence that the DGT's governance framework (involving a careful vetting of staff, higher wages, and a rigorously applied code of conduct) helped promote integrity among tax officers - a major concern among investors in Indonesia.

An assessment of the LTO's performance for each core tax administration function also revealed that satisfaction was the highest with the filing/payment and refund management functions, and lowest with audit and objections. These findings are encouraging in that they suggest the LTO's gold card program has been effective at accelerating the processing of refunds, another major investor concern. But they still point to significant investor concerns over the fairness of the audit and appeals processes.

International comparisons, based on Nielsen's eQ surveys, show that the LTO's score stands out well above the average (Text Table 2). AC Nielsen attributes the positive results partly to large taxpayers' perceptions that the LTO represented a major improvement over what had been in place before. If true, this would suggest that the challenge for the LTO going
Text Table 2. Comparison of Nielsen's eQ Satisfaction Ratings for Selected Asian Economies

\begin{tabular}{lccc}
\hline \multicolumn{1}{c}{ Country } & Pilot Offices & Overall & Public Sector \\
\hline Indonesia (LTO, SRO, & $81,78,74$ & $\ldots$ & $\ldots$ \\
STO) & & & \\
Australia & $\ldots$ & 66 & 74 \\
Hong Kong & $\ldots$ & 75 & 71 \\
Singapore & $\ldots$ & 76 & 76 \\
\hline
\end{tabular}

Source: AC Nielsen LTO, SRO and STO Surveys.

Notes: Overall refers to the average rating for all entities that $\mathrm{AC}$ Nielsen evaluated in each country; public sector refers to the average rating for public sector entities only. In Indonesia the sample is as follows: SRO in central Jakarta and in Batham, STO concerns 15 pilot offices in Jakarta Pusat.

forward would be to maintain this level of satisfaction once the "novelty" has worn off. Similar positive results emerged from a later Nielsen survey of the DGT's Special Region Office (SRO), which like the LTO administers many large businesses and was among the original four pilot tax offices (Text Table 2). In 2004, the SRO adopted many of the reforms

\footnotetext{
${ }^{29}$ The survey involved 126 of the LTO's 300 taxpayers of which 60 percent were multinational companies and 40 percent were local companies. 93 percent of the respondents had dealt with the LTO for 2-3 years.
} 
that were first piloted at the LTO, including its governance framework and accelerated refunds program. The results of the SRO survey, which was conducted in 2005 after the LTO survey, were very similar to those achieved at the LTO in terms of taxpayer satisfaction with the reforms. With the LTO and SRO administering Indonesia's largest taxpayers, who also tend to be the largest investors, the Nielsen surveys suggest that the DGT has made important progress in addressing some of the concerns of major investors. A more recent eQ survey of the STO also showed similarly encouraging results.

Other studies have confirmed the findings that taxpayers' satisfaction is high at the DGT's pilot offices, but that overall taxpayer perception is far less sanguine. For example, the CGI Investment Climate Working Group prepared reports in 2004 and 2005 that looked into the principal investment challenges facing Indonesia. ${ }^{30}$ While acknowledging the many positive results of the LTO and its "customer-friendly" approach to tax administration, the reports found that taxation continued to be among investors' chief concerns. Within the tax area, the major obstacles for business still include several tax administration factors. ${ }^{31}$

Several hypotheses can reconcile the overall negative perception of the tax administration for the investment climate with the numerous taxpayers' surveys that reveal high satisfaction with the DGT pilot offices. These include: (i) incomplete reform of the pilot offices - the pilot offices have introduced a number of changes that are important to investors (better services, electronic filing, quicker refunds, less corruption) but large taxpayers continue to be concerned with other important aspects of the pilot offices' operations (audit, appeals) and with the slow progress in strengthening the ministry of finance's internal investigation capacity; (ii) it takes time for recent administrative reforms to filter through companies' perceptions of tax administration (e.g., improved perceptions by a company's finance department of DGT might take time to filter through to the CEO or other parties in charge of investment plans); and (iii) even if information flows within a corporation are frictionless, given that investment decisions take a long perspective, recent changes in tax administration performance - though welcome - would need to be sustained over time to alter investment behavior (e.g., a Bayesian updating process starting with a sufficiently strong negative prior belief).

\footnotetext{
${ }^{30}$ See the following papers by the Consultative Group for Indonesia, Investment Climate Working Group: (1) Creating Jobs Through Investment: Suggestions from the Donor Community on Improving Indonesia's Investment Climate, October 2004; and (2) Creating Jobs Through Investment: An Update on Efforts to Improve Indonesia's Investment Climate, December 2003.

31 These include: (i) arbitrary implementation of tax regulations by tax officers, leading to additional assessment of taxes; (ii) excessively complex procedures for tax filing and excessive delays in issuing refunds; (iii) a lack of balance in the dispute resolution process and the consequent long periods for resolving tax assessment appeals; and (iv) poor governance among tax officers.
} 


\section{Summary}

The tax administration reforms appear to be a necessary but not sufficient factor in improving the investment climate in Indonesia. Although tax administration has been, and continues to be, a major impediment to investment in Indonesia, taxpayers' satisfaction with the pilot DGT offices is very high. Reforms that achieved particularly good results, as perceived by large taxpayers, are the governance framework and the accelerated refunds. Reforms that remain incomplete include tax simplification and revisions to the tax administration laws. Those that are not functioning as originally intended include the DGT's the audit and appeals processes and the ministry of finance's internal investigation unit.

Improving the investment climate remains crucial to meeting Indonesia's poverty reduction and employment objectives. Since investors continue to view tax administration as a major obstacle to the business environment, the DGT will need to make further progress in this area. A judicious strategy would be for the DGT to extend nationally those investor-friendly reforms that have proven to work well at the pilot offices and to redouble efforts on those reforms that so far have fallen short of expectations.

\section{The Unfinished ReForm AgENDA}

Through 2007, a great deal had been achieved in improving Indonesia's tax administration. The DGT had made good, albeit uneven, progress in implementing its reform agenda and, as a consequence, the tax-to-GDP ratio had steadily increased and governance had improved at the pilot tax offices. However, a great deal remained to be done before the DGT would become a modern and highly effective tax agency. This section sets out the critical initiatives that remain to be completed and summarizes the next phase in the DGT's evolving reform strategy.

Although a pause in the tax administration reforms occurred during 2005 as a new government took stock of the DGT's progress, a cabinet reshuffle in December 2005 brought about renewed momentum to the reforms. This new momentum is largely driven by the efforts of the minister of finance and the DGT's new management team. By the summer of 2006, the DGT had updated its reform plans, which included many pending initiatives from the earlier reform program. Through 2007, the reform strategy has proceeded in three directions with varying degrees of success:

(1) Continuing to expand the pilot tax offices in a carefully phased, step-by-step manner;

(2) further enhancing the DGT's institutional capacity by addressing the remaining, fundamental weaknesses in its headquarters' organizational structure, performance measurement systems, taxpayer services and enforcement programs, human resource management policies, governance controls, and information systems; and, 
(3) Putting in place measures to ensure normal operations continue, services to taxpayers do not decline, and revenue is protected as the modernization strategy is implemented.

\section{A. Rolling Out the Pilot Tax Offices}

The establishment of the LTO and the modernized offices in both the Jakarta Special Region and Jakarta Region I were high-profile events that proved to be greatly successful, as described in earlier sections. The introduction of a functional organizational structure, significantly enhanced taxpayer services activities, an integrated tax administration computer system, and modern office accommodations have substantially boosted the DGT's performance and professional image at those sites.

The LTO has now been operational for more than five years and has yielded good results in terms of revenue collection, service to taxpayers, and governance. ${ }^{32}$ Going forward, the key challenge will be to provide large taxpayers with increasingly better services and to further strengthen the LTO's enforcement capacity in dealing with the more complex compliance risks common to large taxpayers such as international tax issues, aggressive interpretations of the tax laws, and sophisticated tax evasion schemes. In this context, the audit methods used by LTO auditors need to be substantially upgraded.

Given the initial success with piloting a medium-taxpayer office (MTO) in Jakarta, the DGT took a decision in 2006 to roll-out the pilot office to additional regions and by April 2007, 19 MTO's had been established across the country. But along with increasing the number of MTO's, greater efforts are needed to identify those taxpayers that make up the medium-sized taxpayers segment and to tailor the MTO's service and enforcement programs to this group. From this perspective, consideration could be given to expanding the size of each MTO beyond the largest 200 taxpayers in each region. Moreover, the DGT needs to redouble its efforts at customizing its taxpayer services and enforcement programs to the needs and risks of medium-sized taxpayers.

After an initial review of the model small taxpayer office (STO) in September 2006, the DGT commenced the first phase of the STO rollout in mid-June 2007 by extending the STO reforms to 15 tax offices in south Jakarta. By December 31, 2007 the DGT had established 171 new STO's with another 128 planned for implementation in 2008. While the initial results of the STO pilot have been broadly favorable, the STO has not sufficiently customized its taxpayer services and enforcement programs to the specific characteristics of

${ }^{32}$ Reforms that would help improve the administration of small taxpayers include: centralizing the processing of tax returns; developing a start-up guide for new businesses with instructions on how to comply with the basic obligations under the tax laws; introducing a program of advisory visits to the premises of new businesses; creating modern telephone contact centers; ensuring tight control over the timely filing of tax returns and payment of taxes; developing better risk management systems; and designing indirect methods for establishing a tax liability that can be applied to taxpayers who do not maintain proper books of account. 
small taxpayers. Therefore, the expansion of the STO reforms to additional tax offices should be accompanied by the development of more appropriate approaches for administering small taxpayers.

\section{B. Further Enhancing Institutional Capacity}

In addition to deploying the pilot tax offices throughout the country, the DGT's ongoing reform strategy also provides for fundamental reforms in a number of key areas of tax administration. Such reforms include (or should include):

Strengthening the legal framework for tax administration. Although the law on tax administration procedures was amended in May 2007, the legal framework for tax administration still requires further improvement in several important areas, including:

(i) strengthening the DGT's enforcement powers, ${ }^{33}$ (ii) creating a more even-handed system for resolving tax disputes ${ }^{34}$; (iii) eliminating the legal requirement to audit every refund claim; and, (iv) introducing a more appropriate penalty regime. ${ }^{35}$ These improvements are essential if Indonesia's legal framework for tax administration is to achieve an appropriate balance between the powers of the tax authorities and the rights of taxpayers, which is critical for good tax administration.

Reorganizing the DGT's headquarters. DGT management assigned high priority to strengthening its head office, given the critical role that a strong headquarters plays in both managing ongoing operations and designing reform programs. In recent years, the headquarters' organizational structure - which was based partly on tax administration function and partly on tax types - had become increasingly out of step with the DGT's emerging network of functionally organized field offices for large, medium, and small

\footnotetext{
33 The DGT's enforcement powers could be strengthened by: (i) extending the administrative summons power, which is currently limited to criminal tax investigation, to civil tax audits; (ii) authorizing DGT staff (not just auditors) to issue an estimated (default) assessment in cases where a taxpayer fails to submit a tax return on time; (iii) enhancing the DGT's access to information (particularly banking information); and (iv) authorizing the DGT to seize, and not just freeze, bank deposits and accounts receivable of tax debtors without requiring the prior approval of the tax debtor.

34 The system for resolving tax disputes can be made to be more fair by amending the relevant legislation or introducing other institutional changes that would: (i) defer payment of a disputed tax and suspend its collection while the case is under objection or appeal; (ii) allow a judge, under prescribed conditions, to waive the requirement for taxpayers to pay 50 percent of a disputed tax in order to the Tax Tribunal to hear the case; (iii) allow taxpayers to appeal an assessment to the Tax Tribunal if the DGT has not issued a decision on the case within, say, 3 months for individuals and 6 months for companies; and (iv) establish a full-time objections section in each of the DGT's regional offices that reports directly to the head of the appeals section at DGT headquarters (instead of to the head of the regional office).

${ }^{35}$ Indonesia's tax sanctions regime needs to be aligned with international good practice in respect to late payment, underreporting, fraud, and voluntary disclosures.
} 
taxpayers. With this in mind, the DGT reorganized its head office on January $1,2007 .^{36}$ To leverage the new organizational structure, it will now become essential to train senior headquarters' staff in the modern methods for managing a national tax administration.

Simplifying the tax system. Although some progress had been made in simplifying the value-added tax, the business community continues to voice its concerns about the excessive demands and high compliance costs that the tax system imposes on taxpayers. In this connection, there remains considerable scope for simplifying the policy and administrative provisions for each tax, beginning with a redoubling of efforts to further simplify the $\mathrm{VAT}^{37}$ and then extending the effort to the other major taxes. In this regard, tax simplification continues to have substantial potential for both reducing taxpayers' compliance costs and increasing the DGT's administrative efficiency.

> Implementing a balanced set of performance measures. Reliance on the revenue collection target as the main measure of the DGT's performance has damaged integrity and good tax administration practice by creating perverse incentives for arbitrary and inflated audit assessments, delayed refund payments, delays in reaching decisions on objections, and other inappropriate actions. The development of a more balanced set of performance measures would help the DGT to focus on improving the full scope of its tax administration programs and not just on achieving an arbitrary revenue target. To this end, the DGT has drafted a set of key performance indicators to underpin its strategic plan and now needs to take steps to put these indicators into operation.

Designing a new human resource (HR) management regime. Such a system is critical for creating incentives for improved performance and appropriate behavior by managers and staff. Under current arrangements, salary increases and promotions for DGT staff are linked to performance to only a very limited extent, even at the modernized offices. This situation seriously hampers the DGT's ability to reward top performers and create incentives for high performance and noncorrupt behavior. In this context, fundamental changes need to be made to the DGT's HR management policies in job classification, remuneration, promotion, and staff evaluation. Importantly, policies for increasing staff remuneration need to be linked to efforts at "right-sizing" the DGT's work-force.

\footnotetext{
${ }^{36}$ Among other things, the new headquarters structure provides for three new directorates to manage the modernization reforms, a strategic planning unit, and a criminal investigation unit to investigate criminal violations of the tax laws in cooperation with the MOF's Inspector General.

${ }^{37}$ As mentioned in section IV, VAT administration could be further simplified by: (1) eliminating the requirement that all refund claims must be audited; (2) substantially reducing the numerous lists of purchase and sales invoices required as supplements to the VAT return; (3) discontinuing the requirement for VAT refund claimants to submit the original copies of all purchase and sales invoices; and (4) streamlining the VAT refund process for taxpayers without gold card status.
} 
Enhancing governance controls. Some positive steps have been taken in recent years to improve governance, including the introduction of a code of conduct at the LTO and the other pilot tax offices as well as the establishment of an internal investigations unit within the MoF's Inspectorate General. The pilot office reforms are integral to Indonesia's business climate and should be rolled-out nationally as quickly as possible. Similarly, the good progress that has been made in creating the MoF's internal investigation unit needs to be capitalized on by ensuring that serious cases of misconduct by tax officers result in severe administrative penalties and, where appropriate, are referred for prosecution. As part of this effort, the authorities need to monitor and publicize the numbers of investigations that have been conducted and their results.

> Further strengthening the DGT's enforcement programs. While the DGT has introduced some improvements in the enforcement area, its core enforcement programs still require substantial upgrading. In particular, major improvements are needed to the DGT's programs for cleaning up the taxpayer register, identifying potential registrants, controlling nonfilers, collecting tax arrears, and, most importantly, auditing taxpayers. In each of these areas, the DGT needs to overhaul its approach to setting operational targets, risk assessment systems (including the cross-matching information on tax returns to information reported by third parties), and the methods and techniques used by front-line enforcement staff. ${ }^{38}$

Modernizing information systems. Over the last several years, the DGT's efforts at strengthening its IT systems has helped to improve compliance and increase tax collection. However, the lack of a unified IT system is a major impediment to further improvements. Other priority areas include the need to expand electronic filing and other electronic services, automate risk assessment systems and third-party information matching, develop telephone contact centers and centralized sites for processing paper tax returns, and improve management information on core tax administration processes. The establishment of the DGT's first data processing center, which was scheduled to be implemented in early 2008, is an important step forward. However, the DGT urgently needs to develop a comprehensive information technology strategy to guide its future IT reforms.

\footnotetext{
${ }^{38}$ In this context, the DGT's VAT refund audit process is in particular need of modernization. Under a modern refund audit program, the entire stock of refund claims is ranked according to risk and, to the extent resources are allocated to refund audits, those with the greatest risk would be audited prior to payment while those with less risk would be audited after a refund has been paid or not all. This arrangement coupled with the development of modern refund audit procedures would permit the DGT to perform VAT audit refunds more effectively. Such reforms could also have a major impact on the overall audit program as the DGT would be free to assign resources to refund audits and nonrefund audits on the basis of risk as opposed to the current situation where nonrefund audits receive only those resources remaining after refunds are audited.
} 


\section{Safeguarding Revenue}

The DGT's ongoing tax administration reforms pose some risks to revenue collection as existing forms of administration are replaced by new and less familiar ones. To mitigate these risks, the DGT needs to implement measures that ensure revenue collection is not adversely affected as the reforms take hold. For this purpose, the DGT may consider reviving the revenue generation initiative, which it had introduced successfully in 2002.

Under the revenue generation initiative, DGT headquarters set operational targets for the number and type of enforcement actions (audit, arrears collection, etc.) that were to be taken by each of its core enforcement programs (audit, arrears collection, etc.) along with forecasts for the amount of revenue that would be recovered through these actions. It then carefully monitored performance against targets, and held staff accountable for results.

This initiative proved highly effective in mobilizing substantial amounts of tax revenue through 2005. After 2005, however, the DGT discontinued the systematic reporting on the amount of revenue that was generated by each of its enforcement programs. Reestablishing the revenue generation initiative may provide the DGT with an effective option for safeguarding revenue as its modernization program continues to unfold. ${ }^{39}$

\section{LESSONS AND CONCLUSIONS}

Since 2002, Indonesia's tax administration reforms have made significant contributions to the country's fiscal adjustment program and have also placed the DGT on a reform path that has continued through 2007. From this perspective, the reforms can be considered to have been successful in achieving their objectives. Yet despite the broadly positive results, it is nevertheless clear that some reforms have been implemented more fully than others and, in a number of important areas, much further progress is still needed. In this final section, the paper identifies the key success factors and major impediments to reform along with the main conclusions that may be drawn from Indonesia's experience in reforming tax administration within the context of a fiscal adjustment program.

\section{A. Key Success Factors}

Several factors have contributed significantly to the success of the tax administration reforms over the last several years. As the DGT continues to move forward with its reform agenda, it will be important to preserve these key success factors, which have included:

\footnotetext{
${ }^{39}$ After 2005, the DGT discontinued the systematic reporting on the amount of revenue that was generated from each of its core enforcement programs: registration, arrears collection, audit, and late filer programs. Refer to Chapter IV for details.
} 
Direct linkages with the fiscal adjustment program. Strong pressure to increase revenue from non-oil and gas sources, coupled with the limited agenda for tax policy reform, focused the government's attention on tax administration reform as an integral element in its strategy for achieving fiscal sustainability. The linkage of the tax administration reforms to the government's high level policy objectives was crucial for ensuring that sufficient amounts of resources (political, budgetary, and staffing) were made available to support the reform effort. It also made the reforms more consequential to DGT officials, who initially were not necessarily convinced of the reform program's benefits.

Strong political support. From the outset, the reforms received strong support from the minister of finance and other senior government officials. This support was manifested in a number of ways, both big and small. Most importantly, the finance minister allocated adequate resources to the reforms, monitored developments to ensure that the reforms remained on track, and intervened in a timely manner to overcome obstacles. Less obviously, but equally important, the minister and other senior government officials made significant efforts at explaining the reforms to the media and taxpayer population, encouraging the DGT staff to implement the reform agenda, and recognized and rewarded good performance. These efforts are continuing.

Appointment of capable staff to lead the reforms. Among the most important decisions that the authorities had taken at the beginning of the reform program was to appoint a capable group of DGT officials to lead the reforms. These staff was highly motivated, open to new approaches in tax administration, and possessed strong leadership skills. They worked long hours on designing and implementing the reforms while at the same time holding down their regular operational positions. Their dedicated efforts were truly impressive and provide yet another example of the close relationship that exists between efforts and results in tax administration reform.

Achievable targets to deliver early results. To avoid the DGT from becoming overwhelmed by a comprehensive reform program that exceeded its implementation capacity, the initial phase of reforms in 2002 was purposely restricted to a relatively small number of priority initiatives that the DGT could effectively manage. This approach allowed early successes to be registered, which built confidence within the DGT to take on increasingly more challenging reforms. In this way, the modestly ambitious reforms that commenced in 2002 catalyzed commitment and enthusiasm for the more ambitious reform program that was to follow.

Phased implementation. Wherever possible, new initiatives were tested at one or more pilot sites before being rolled out nationally. For example, new organizational structures, human resource management policies, and IT initiatives were first piloted in the LTO. This approach facilitated better control and monitoring during the implementation stages and allowed teething problems to be dealt with more expediently. Once the success of these initiatives had been confirmed, including through feedback from taxpayers, the reforms were duplicated at 
the medium-taxpayer office and are now being extended to at all small taxpayer offices as an integral part of the DGT's modernization strategy.

Private sector stakeholders involvement. From time to time, the DGT met with representatives of the business community to update them on progress with the tax administration reforms and to solicit feedback on proposals. The DGT also made great effort to invite business representatives to significant events, such as new office openings offices or new initiative launches. Apart from providing valuable feedback that assisted in the design and implementation of modernization initiatives, involving the private sector business community also secured its support for the reforms, which had further positive impacts on the political support for the project.

Appropriate use of policy conditionality and technical assistance. The policy conditionality that accompanied the financial assistance from international agencies helped to catalyze Indonesia's tax administration reforms. Similarly, the Indonesian authorities made excellent use of technical assistance from these agencies at each stage in the reform process. When combined with strong political commitment for reform by governments, the experience from Indonesia shows that policy conditionality and technical assistance can play an important role in advancing tax administration reform.

\section{B. Major Impediments}

In addition to factors that helped the tax administration reforms succeed, there were also a number of constraints that have impeded the reform effort over the years. The success of the reforms going forward depends critically on the steps that the Indonesian authorities take to ease these constraints, which include:

Political constraints. Despite strong political support for the reforms from some key officials, there were a number of critical areas where interests at both the executive and administrative levels within government, as well as powerful interests outside government, were not always aligned with the reforms and inhibited, at times, the implementation of some key initiatives. This was particularly the case with the efforts at overhauling the DGT's audit program, which to date have produced few results despite being crucial to the tax administration reform strategy. Similarly, the initiative to register additional numbers of high income taxpayers was hindered by the refusal of many third parties, such as professional associations, to provide details about their members to the DGT. When faced with this situation, the DGT itself was reluctant to adopt a firm stance, instead opting to seek legal clarification that was rarely decisive.

Legal and procedural constraints. Legal constraints sometimes obstructed progress on the implementation of reforms. Some reforms required legislative amendment, which inevitably caused long delays. Other delays resulted from the requirement for the DGT to issue a formal decree, signed by the Director General, to effect changes in instructions regarding operational methods and procedures. For example, the introduction of the "gold card scheme," which 
was designed to speed up the VAT refund process, not only required decrees for operational instructions, but also required each taxpayer to be named in a decree as being awarded gold card status. The extensive requirement for issuing DGT decrees and the lack of managerial empowerment severely restricted the pace at which detailed operational matters could be reformed.

Organizational constraints. Operational pressures meant that most key players responsible for designing the reforms were also expected to continue carrying out their regular operational duties, which made it difficult to maintain enthusiasm for the reform program over a prolonged period. From this perspective, a more productive arrangement may have been to create a full-time modernization team and to relieve the staff assigned to this team from other responsibilities. Similarly, the DGT's policy of mandatory rotation of staff and managers every two years - though largely an anti-corruption measure - greatly impedes the development of expertise as managers are frequently rotated into areas in which they have little or no experience. Finally, the reform effort was further complicated by fragmented implementation responsibilities at headquarters: for example, despite the establishment of a dedicated headquarters team to improve compliance with tax filing obligations, little progress was achieved on this initiative because critical elements were also required to be performed by other departments at headquarters.

Measurement and incentive constraints. Traditionally, the DGT had relied on the annual revenue collection target as the main measure for judging and rewarding the performance of its regional and district directors. This reliance on a narrow measure of performance, however, created perverse incentives for all sorts of inappropriate practices-including arbitrary audit assessments and delaying the processing of refunds - in order to achieve the assigned collection target. On the other hand, the positive results that were achieved by the revenue generation program - which established targets for each of the DGT's enforcement programs - demonstrates that substantial gains in tax administration can be realized by setting meaningful and reasonably ambitious performance measures, and holding staff accountable for their achievement. 


\section{Conclusions}

Several conclusions may be drawn from the Indonesia's experience in reforming tax administration. Some conclusions reaffirm lessons learned from tax administration reform in other countries, while other conclusions offer new insights. These include:

- $\quad$ Since 2002, Indonesia's tax administration reforms have been successful in advancing the country's fiscal adjustment program. The tax administration reforms had a strong, positive impact on the tax yield and a positive, though difficult to quantify, effect on the investment climate.

- $\quad$ Linking tax administration reform to a government's wider fiscal adjustment program can both assist fiscal adjustment and improve tax administration. Given the gestation period for designing and implementing tax administration reforms, the sooner such reforms can be incorporated into an adjustment program the better.

- Tax administration reform can help increase the tax yield by raising additional amounts of enforced and voluntary tax collections. Programming these gains should be based on a coherent framework, such as that set out in Section II and Appendix I, with realistic estimates for increasing collections that are linked to concrete administrative measures for bringing about the targeted increases.

- In the short-term, enforced collections may provide a substantial source of additional tax revenue. However, because these collections typically account for a relatively small share of tax revenue, very high growth rates are required to have an appreciable impact on the tax yield. The Indonesian experience demonstrates the practical difficulties of achieving high growth rates in enforced collections year after year.

- $\quad$ Over the medium-term, increasing voluntary collections (by raising taxpayers' compliance rates) is the key way that tax administration can help sustain and expand the tax yield. Therefore, tax agencies should be encouraged to measure tax compliance, identify reasons for noncompliance, and develop appropriate compliance-enhancing strategies.

- $\quad$ Tax administration reform can be a necessary (but not a sufficient) condition for improving a country's investment climate. A tax agency can help boost the investment climate through measures that lower compliance costs faced by taxpayers and promote integrity among tax officers. Indonesia achieved promising, initial results by piloting the careful vetting of tax officers, providing sufficiently high salaries, establishing clear standards of conduct that were effectively communicated to taxpayers and tax offices, and accelerating the processing of tax refunds.

- The good results that have been achieved in improving Indonesia's tax administration were due, in part, to a reform strategy that focused initially on a few key initiatives. 
This approach allowed early successes to be registered in the short-term and helped build confidence within the DGT to take on increasingly more challenging reforms over the medium-term.

- $\quad$ Strong political commitment was critical to the success of Indonesia's tax administration reforms. This commitment was most evidenced by the government's willingness to place tax administration reform high on its reform agenda, allocate resources (staff, budgetary, and technical assistance) to support the reforms, and appoint capable staff to lead the reform effort.

- Technical assistance and policy conditionality can play an important role in helping tax agencies to design and implement reform programs. However, ownership of the reform process by a country's tax agency is indispensable for sustaining the reforms over time.

- There remains ample scope for Indonesia to increase the tax yield and stimulate the investment climate through further improvements in tax administration. In this regard, the strategic plan that the DGT's new management formulated in 2006 provides a sound basis for strengthening revenue collection and promoting fiscal adjustment over the coming years. The preliminary 2007 tax collection estimates vindicate these reform efforts. 


\section{Appendix I. Analytical Framework: Tax Administration and the Tax Yield}

The linkages between tax administration and the tax yield that were described qualitatively in Section II are now presented more precisely in mathematical terms. ${ }^{40}$ To isolate the role of tax administration, the discussion assumes no changes in tax policy, structural shifts in the economy that affect relative tax burdens, or changes in any factors that affect the tax yield other than those involving tax administration.

Defining the tax yield. The tax yield is commonly defined as the ratio of tax revenue to GDP. With tax revenue consisting of both voluntary payments by taxpayers and enforced collections by the tax agency, the tax yield may be expressed as follows:

(1) $\frac{T}{G D P}=\frac{T V+T E}{G D P}$

where:

$T=$ Total tax collection

$T V=$ Taxes collected voluntarily from taxpayers

$T E=$ Taxes collected through enforcement by the tax agency

$G D P=$ Gross domestic product

Accounting for changes in the tax yield. By manipulating equation (1), the sources of change in the tax-to-GDP ratio can be expressed by the following equation:

$$
\left(\frac{\dot{T}}{G D P}\right)=\alpha \dot{T V}+(1-\alpha) \dot{T E}-G \dot{D P}
$$

where:

$\alpha=$ the proportion of voluntary tax collection to total tax collections or $\frac{T V}{T V+T E}$

$(1-\alpha)=$ the proportion of enforced collection to total tax collections or $\frac{T E}{T V+T E}$

$\bullet=$ percentage change in a variable

Equation 2 demonstrates that changes in the tax-to-GDP ratio are accounted for by changes in the growth rates of voluntary and enforced collections, weighted by their relative shares in total tax collection ( $\alpha$ and $1-\alpha$ ), and the growth rate of GDP. The equation clarifies an important point made in the body of the paper that the small share of enforced collections (typically less than 10 percent) implies that a relatively large increase in the growth rate of

\footnotetext{
${ }^{40}$ This section benefited from the guidance provided by Michael Keen and Anthony Pellechio.
} 
enforced collection is required to produce a significant impact on total collections. ${ }^{41}$ Conversely, the large share of voluntary collections (commonly greater than 90 percent) means that a relatively small increase in their growth rate will have a significant impact on the tax yield.

This point has important implications for the design of tax administration reforms that are strongly focused on increasing tax revenue. While it may be possible to raise the tax yield in the short-term through large increases in enforced collections, it is not realistic to expect a tax agency to achieve high growth rates in these collections year after year that would be required to continuously increase the tax yield. Over the medium-term, therefore, increasing the tax yield through tax administration improvements depends critically on tax agency's capacity to increase voluntary collections.

Expressing changes in voluntary collections. Voluntary collections (TV) can be defined as the product of the total amount of taxes that taxpayers are required to pay under the tax laws (potential tax collections, TP) and the proportion of potential taxes that taxpayers actually pay (i.e., the voluntary compliance ratio, $v$ ). As such, voluntary collections are expressed as follows:

$$
\begin{aligned}
& T V=v \cdot T P \\
& \text { where: } \\
& T V=\text { Taxes collected voluntarily from taxpayers } \\
& T P=\text { Amount of (potential) tax collections if taxpayers fully comply with tax laws } \\
& v=\frac{T V}{T P}
\end{aligned}
$$

As indicated in equation 3 , an increase (decrease) in the voluntary compliance ratio $(v)$ will lead to an increase (decrease) in the amount of voluntary collections as taxpayers come to pay a larger (smaller) share of their true tax liability. A tax agency can raise the voluntary compliance ratio, and, hence, increase voluntary collections, by enhancing the effectiveness of its compliance facilitation and compliance enforcement programs. As taxpayers improve their compliance rates in response to these programs, voluntary collections will increase. Turning to the second element in equation (2), potential tax collections $(T P)$ are responsive to changes in GDP as increases in income and sales give rise to higher tax liabilities. The degree of responsiveness is referred to as the revenue elasticity of the tax system, which is

\footnotetext{
${ }^{41}$ Assuming 90 percent of the taxes are paid voluntarily, equation 2 indicates that achieving a 5 percent increase in the tax yield would require a $5 \frac{1}{2}$ percent increase in voluntary collections (TV) in the absence of any increase in enforced collections. Achieving the same increase in the tax yield through enforced collections (TE), without any increase in voluntary collections, would require enforced collections to grow at a substantially higher growth rate (i.e., 50 percent) due to its relatively small share in total revenue.
} 
defined here as the percentage change in voluntary tax collections divided by the percentage change in GDP, ${ }^{42}$ or:

$$
\varepsilon=\frac{(\Delta T V / T V)}{(\Delta G D P / G D P)}
$$

where:

$T V=$ taxes collected voluntarily from taxpayers

$G D P=$ gross domestic product

If the elasticity $(\varepsilon)$ is greater than 1 , then the tax system is said to be "revenue elastic" and taxes will rise proportionally more than national income. For example, if $\varepsilon$ equals 1.2 , then for every 10 percent increase in GDP tax collections rise by 12 percent. In contrast, if the elasticity is less than 1 , then the tax system is "revenue inelastic." Hence, if $\varepsilon$ equals 0.8 then a 10 percent increase in GDP will yield only an 8 percent increase in taxes.

Now, the growth rate of voluntary collections can be expressed as:

$$
(\dot{T V})=(\dot{v}+\varepsilon \cdot G \dot{D} P)
$$

By substituting equation 4 into equation 2, changes in the tax yield can then be expressed as:

$$
\left(\frac{\dot{T}}{G D P}\right)=\alpha(\dot{v}+\varepsilon \cdot G \dot{D} P)+(1-\alpha) \dot{T E}-G \dot{D} P
$$

The first term on the right-hand side of equation (5) shows that voluntary collections increase with increases in both the voluntary compliance ratio $(v)$ and GDP. For example, if the voluntary compliance ratio were to increase by 5 percent (e.g., from 60 percent of potential collections to 63 percent of potential collections) and GDP were to increase by 10 percent with an elasticity of unity (1) then voluntary collections would increase by 15 percent. We now turn to the second term on the right-hand side, enforced collections (TE).

Expressing changes in enforced collections. Enforced tax collections (TE) are determined by two variables: the total amount of foregone revenue resulting from noncompliant taxpayers and the rate at which the tax agency recovers the foregone revenue. The first of

\footnotetext{
${ }^{42}$ The elasticity of the tax system excludes any legislated changes in tax policy or improvements in tax administration. As such, the elasticity measures only the built-in responsiveness of the tax revenue to GDP growth.
} 
these two variables, foregone revenue, is the product of the total amount of taxes due according to the tax laws (potential tax collections, $T P$ ) and the rate of noncompliance among taxpayers (1-v, the complement to the rate of compliance, $v)$. The second variable, the revenue recovery ratio $(r)$, can be defined as the proportion of foregone revenue that a tax agency actually recovers each year. Taken together, the amount of enforced collections can be expressed $\mathrm{as}^{43}$ :

$$
\begin{aligned}
& \text { TE }=r \cdot(1-v) \cdot T P \\
& \text { where: } \\
& r=\text { revenue recovery ratio }=T E /(T P-T V)=\frac{T E}{T P \cdot(1-v)} \\
& (1-v)=\text { noncompliance ratio }=1-(T V / T P) \\
& T P=\text { potential tax revenue }
\end{aligned}
$$

Based on equation (6) and recalling that potential tax revenue grows in line with the elasticity of the tax system and changes in GDP, the growth rate of enforced collections can then be expressed as:

$$
\dot{T E}=\dot{r}+(1-v)+\varepsilon \cdot G \dot{D} P
$$

An interesting implication of equation 7 is that the growth rate of enforced collections will decrease with increases in the voluntary compliance ratio $(v)$ for a given elasticity and a given amount of GDP. This results from the fact that as taxpayers increases their compliance rates, the "supply" of foregone revenue that a tax agency can potentially recover will decrease.

Before closing the discussion of enforced collections, it is important to point out that changes in the voluntary compliance ratio $(v)$ and its complement the noncompliance ratio (1-v) are not independent of each other: as the voluntary compliance ratio increases, the noncompliance ratio necessarily decreases and vice-versa. The precise relationship between the two can be shown to be:

\footnotetext{
${ }^{43}$ To clarify, if the potential amount of taxes is 100 but taxpayers' voluntarily pay only $40(\mathrm{v}=.40)$ then the total amount of foregone revenue would be 60 . If the tax agency succeeds in recovering 10 percent of the 60 in foregone revenue $(r=.10)$ then enforced collections (TE) would be 6 .
} 


$$
(1-\dot{v})=-\dot{v} \cdot\left(\frac{v}{1-v}\right)
$$

This relationship means that the noncompliance ratio $(1-v)$ will decrease at the rate that the compliance ratio increases adjusted for by the proportion of the compliance ratio $(v)$ to the noncompliance ratio $(1-\mathrm{v})$. When the compliance ratio is greater than the noncompliance ratio $(v>0.5)$, the noncompliance ratio will decrease at a faster rate than the compliance ratio increases. Conversely, when the compliance ratio is less than the noncompliance ratio $(v<0.5)$ then the noncompliance ratio will decrease at a slower rate than compliance ratio increases. Taking this into account, the growth in enforced collections can be more precisely stated as:

$$
\dot{T E}=\dot{r}-\dot{v} \cdot\left(\frac{v}{1-v}\right)+\varepsilon \cdot G \dot{D} P
$$

Equation (9) shows that a tax agency's ability to increase the growth rate of enforced collections depends on the capacity of its compliance enforcement programs to raise the revenue recovery ratio $(r)$. This ratio will increase to the extent that a tax agency can collect a larger proportion of foregone tax revenue owed by noncompliant taxpayers. As described earlier, identifying and recovering taxes from businesses and individuals who fail to register for taxation, do not file their tax returns and pay their taxes on time, or underreport their tax liabilities are all ways in which a tax agency can increase the revenue recovery ratio $(r)$.

The full expression. Now, by substituting equation 9 into equation 5 and re-arranging terms, the factors accounting for changes in the tax yield can be expressed as:

$$
\left(\frac{\dot{T}}{G D P}\right)=\alpha \cdot \dot{v}+(1-\alpha) \cdot \dot{r}-(1-\alpha) \cdot \dot{v} \cdot\left(\frac{v}{1-v}\right)-(1-\varepsilon) \cdot G \dot{D} P
$$

Equation (10) provides the full framework for analyzing the impact of tax administration on the tax yield. It shows that a tax agency can affect the tax yield through the four terms on the right hand side of the equation. The meaning of each of these terms is summarized below along with a simple example to drive home the analysis.

The first term on the right-hand side of equation 10 represents the impact that changes in voluntary compliance ( $v$, weighted by the share of voluntary collections in total tax revenue) has on the tax yield. The tax agency can influence the voluntary compliance ratio by improving the effectiveness of its compliance facilitation and compliance enforcement programs. To the extent that taxpayers adjust their compliance patterns in response to these programs, the voluntary compliance ratio $(v)$ will increase and voluntary collections will grow (the indirect effect of compliance enforcement). 
The second terms illustrates how the tax yield is affected by changes in the tax agency's capacity to recover taxes that were legally due but not voluntarily paid by taxpayers. As a tax agency strengthens its compliance enforcement programs, the recovered revenue ratio $(r)$ will rise and the amount of enforced collections will increase.

The third term shows that increases in the voluntary compliance ratio $(v)$ can, to some degree, diminish the revenue impact of a tax agency's compliance enforcement programs by reducing the total amount of foregone revenue that the tax agency could potentially recover. The magnitude of this "dampening" effect will depend on the proportion of compliance to noncompliance ratios $\left(\frac{v}{1-v}\right)$ and the share of enforced collections in total collections $(1-\alpha)$.

The final term shows the impact that increases in GDP has on the tax yield. Growth in GDP will increase (decrease) the tax-to-GDP ratio to the extent that the elasticity of the tax system is greater (less) than 1.

To bring all the pieces together, consider the case where a government seeks to increase the tax yield from 10.0 percent of GDP to 10.5 percent of GDP (i.e. a 5 percent increase) strictly through improvements in tax administration. As with the earlier examples, assume that the share of voluntary collections in total tax collections $(\alpha)$ is 90 percent (and, therefore, enforced collections $(1-\alpha)$ equals 10 percent), the voluntary compliance ratio $(v)$ is 0.60 (and, consequently, the noncompliance ratio $(1-v)$ is 0.40 ), and that the elasticity of the tax system equals 1 . Inserting these figures into equation 10 would yield:

$$
.05=0.9 \cdot \dot{v} \quad+0.1 \cdot \dot{r} \quad-0.1 \cdot \dot{v} \cdot 1.5 \quad-0
$$

Using this framework, fiscal economists and tax administration specialists could determine the feasibility of achieving the targeted increase in the tax yield by assessing the extent to which a tax agency could increase the voluntary compliance ratio $(v)$ and the revenue recovery ratio $(r)$ through improvements to its compliance facilitation and compliance enforcement measures.

So if it were to be determined that a tax agency's measures could increase both the voluntary compliance ratio by, say, $4 \frac{1}{2}$ percent $(0.045)$ and the revenue recovery ratio by 17 percent $(0.17)$ then the framework would suggest that the tax yield would rise by about 5.1 percent, thereby exceeding the target. If, on the other hand, it were to be determined that a tax agency could only increase the voluntary compliance ratio by, say, 3 percent and the revenue recovery ratio by, say, 10 percent then the framework would indicate that the tax yield would rise by only 3.5 percent, thereby falling short of the target. In this situation, the authorities would either need to reduce the targeted increase in the tax yield or introduce a more ambitious set of tax administration measures. 


\section{Appendix II. VAT Revenue Projections}

This appendix details the methodology used to derive the impact of tax administration reform on VAT collection. As detailed in Section VI, changes in VAT collection can arise from three sources: (i) changes to the nature of the tax itself (tax policy changes); (ii) structural economic changes that affect the VAT base; and (iii) tax compliance changes - which are primarily the result of the tax administration effectiveness (actual or perceived).

With no tax policy changes occurring over the reform period, VAT buoyancy can only stem from the remaining two sources. The revenue impact of tax administration reforms is derived as a residual between actual VAT collected and VAT that should have been collected based on the observed structural economic changes. More specifically, the methodology, which is based around a GDP-decomposition of the VAT base (Zee, 1995), involves the following steps:

1. Calibrate VAT projections for 2001 to actual revenue collection for that year.

a) Private final consumption in the economy is estimated (in a simple macro-based model);

b) The economy-wide rate of activities exempted from VAT is applied to the estimated final consumption base; this provides the taxable base for the VAT.

c) The statutory VAT tax rate is applied to that base; this provides an estimate of potential VAT collection.

d) The VAT tax gap is calculated. The tax gap is the difference between potential VAT and actual VAT collection; it measures the degree of tax compliance/leakage.

2. Project VAT collection for 2002 to 2006 assuming an unchanged compliance behavior (i.e., holding the tax gap constant as the 2001 level). These projected VAT revenue take into account changes in the GDP composition (e.g., import growth exceeding that of export, which is revenue positive for VAT collection) but do not allow for improved compliance due to tax administration efforts, and also assume that the share of exempted sector is unchanged (which is a realistic first-order assumption since no changes to the VAT base and rate took place during the period).

3. Calculate the revenue impact of tax administration reforms by taking the difference between actual VAT collection and VAT collection projected based on changes in the economic structure (This also allows to calculate the reduction in the tax gap/improvement in tax compliance).

A complication in the above methodology is to calculate the aggregate VAT exemption rate. A standard methodology to estimate this exemption rate is to use a GDP decomposition framework and make several adjustments to the taxable base depending 
on exemptions and threshold included in the VAT law (Zee, 1995). This requires a comprehensive and detailed analysis of economic sectors and their interactions. Information is mainly obtained from national income accounts, input-output tables, and CPI. Fortunately, such a detailed analysis was undertaken by Marks (2005) for the year 2000. Marks finds the revenue potential of the VAT was 5.7 percent of GDP; whereas actual collection was 2.8 percent of GDP which gives an estimated VAT tax gap of 51 percent or 2.9 percent of GDP.

Using the compliance rate obtained by Marks (2005) and actual revenue collection, the economy's exemption rate can then easily be calculated as a residual for the year $2000 .{ }^{44}$ Assuming the exemption rate is unchanged from 2000 onwards (which is a reasonable firstorder assumption, as argued above), a compliance rate is derived (by matching projected and actual VAT collection) for 2001, the year prior to the tax administration reforms. This provides the computations needed for step 1; steps 2 and 3 are straight-forward. Table 4 (main text) presents the results of these computations, and reveal that tax administration reform efforts account for 0.27 percentage points of GDP in revenue over performance (more than half of the increased tax yield).

Table 4 also presents some standard VAT performance indicators, namely VAT efficiency ratios (also productivity ratios). The first one, the VAT efficiency is defined as the ratio of VAT revenues to GDP divided by the standard VAT rate (expressed as a percentage). It is widely used as a gauge of the extent to which the VAT bears uniformly upon a broad base, with a low ratio taken as evidence of tax erosion often due to a proliferation of exemptions or to weak tax compliance and enforcement. In Indonesia, the efficiency ratio was 30.5 percent in 2001, which is lower than the 35 percent average ratio reported in Ebrill let al. (2001) for Asia and Pacific countries (the world-wide average ratio they computed is 34 percent). This ratio implies that a 1 point increase in the VAT rate is associated in Indonesia with a 0.305 percentage point of GDP increase in VAT revenue. Thanks to improved compliance linked to the tax administration reforms, by 2006, the impact of 1 point of VAT increased to 0.353 percentage point of GDP - a 16 percent increase in the productivity of the VAT in Indonesia.

Although widely used, VAT efficiency ratios have important limitations, as detailed in Ebrill et al. (2001). For this reason, two other VAT performance diagnostic tools are also presented, namely VAT "C-efficiency" (out of total and private consumptions). The "C-efficiency" ratio is defined as the ratio of the share of VAT revenues in (total or private) consumption (rather than GDP) to the standard rate. The advantage is that this ratio is normalized at 100 percent (i.e., 100 represents a uniform tax on consumption; zero rating would reduce that number,

\footnotetext{
${ }^{44}$ Marks reports revenue collection of 3.2 percent of GDP as he includes revenue collected from the luxury and sales tax (since the government does not readily report the breakdown between these two taxes, only their aggregate collection). This generates a lower VAT tax gap in his analysis.
} 
however, a break in the VAT chain due to exemptions - and cascading - could generate a ratio over 100 percent). In Indonesia, all VAT performance indicators point to a significant increase over the reform period (Table 4). 


\section{References}

Asian Development Bank and World Bank, 2005, Improving the Investment Climate in Indonesia, Joint ADB-WB Report, May 2005.

Daniel, James, Davis, Jeffrey, Fouad, Manal, Van Rijkeghem, Caroline, 2006, "Fiscal Adjustment for Stability and Growth," Pamphlet Series No. 55, International Monetary Fund, Washington, D.C.

Dubin, Jeffrey, Graetz, Michael J., Wilde, Louis L., 1990, “The Effect of Audit Rates on the Federal Income Tax, 1977-86,” National Tax Journal, Vol. 43, pp. 395-405.

Dubin, Jeffrey, 2004, "Criminal Investigation Enforcement Activities and Taxpayer Noncompliance,” paper written for Internal Revenue Service Research Conference, June 2004.

Ebrill, Liam, Michael Keen, Jean-Paul Bodin and Victoria Summers (2001), The Modern $V A T$, International Monetary Fund, Washington DC.

Indonesia-Japan Economic Working Team, 2004, "Strengthening Tax Policy Through Tax Reform," pp. 15-16.

Marks, S.V., 2005, "Proposed Changes to the Value Added Tax: Implications for Tax Revenue and Price Distortions," Bulletin of Indonesian Economic Studies, Vol. 41, No. 1, 2005: 81-95

Organization for Economic Co-Operation and Development, various years, OECD Outlook.

Organization for Economic Co-Operation and Development, various years, OECD Revenue Statistics.

Plumley, Alan H., 1996, "The Determinants of Individual Income Tax Compliance: Estimating the Impacts of Tax Policy, Enforcement, and IRS Responsiveness," Internal Revenue Service Publication 1961 (rev. 11-96) pp. 35-36.

Toder, Eric, 2007, What is the Tax Gap?, prepared for the American Bar Association Conference on the Tax Gap, June 21, 2007.

Zee, H. H., 1995, "Value Added Tax," in P. Shome (ed.) Tax Policy Handbook, International Monetary Fund, Washington, D.C. 